Chapter 9

\title{
Credibility and trust in risk communication
}

\author{
ORTWIN RENN and DEBRA LEVINE
}

\section{Introduction}

Institutions and social actors involved in managing risk have to cope with the problem of legitimating their decisions and policies in a political arena, in which the major stakeholders are still defining their social role and in which the public is observing a confusing mix of controversial and often contradictory information. Furthermore, in spite of the newness of the new risk paradigm in society, two opposing camps have evolved: one supporting and promoting large technologies and further economic growth, and the other opposing large-scale technologies, supporting conservation efforts, and favoring a zero or low growth economy. In the cultural theory of risk these two groups have been labelled as center and periphery (Douglas and Wildavski 1982) or entrepreneurian and sectarian (Rayner and Cantor 1987). The two camps have formed their own institutions and support groups, and try to convince the general public that their perspective on risk is the one to pursue. The rigidity of their positions has polarized the public debate.

In this situation all parties, in particular the two opposing camps, rely on trust and credibility for their communication effort to impress the audience or even to influence their attitudes (Blair 1987; Zimmermann 1987). Credibility of information sources is, therefore, a key issue in risk communication. At the same time it is the major social resource that may determine which group or fraction will finally shape social risk policies and enhance its social power. Credibility is still a scarce resource for which different groups compete in their communication process. As a result, credibility issues have to be studied in the context of the arena in which they occur. If the arena is characterized by a new evolving power structure and embedded in a substantial value change situation, credibility of sources is a major medium of power control and social influence in a competitive market. It may well be the decisive agent in determining the losers and winners in such a context.

The specific arena conditions of the risk debate with its opposing camps is one major reason for separating risk communication from other social contexts in which institutions and groups compete for public approval and trust175

R.E. Kasperson and P.J.M. Stallen (eds.), Communicating Risks to the Public, 175-218. (C) 1991 Kluwer Academic Publishers. Printed in the Netherlands. 
worthiness. The second reason is the novelty of stochastic reasoning in public and private policy making (Keeney and von Winterfeldt 1986). The process of decision making in most legal and political arenas traditionally focuses on deterministic consequence analysis. Anticipating the most likely impacts of a decision and weighing the associated costs and benefits of different options, in terms of formal analysis or by "bootstrapping" (Fischhoff et al. 1979), is the major pathway of policy making. The question of how to incorporate relative frequencies in the decision process, (i.e. balancing options with different compositions of magnitude and probability) has not been adequately addressed and assimilated by the political decision system. A variety of strategies to cope with this new challenge has evolved over time, including technocratic decision making through expert committees or ignoring probabilistic information altogether. The use of probabilities in decision making requires new rationales for evaluating policy options and necessitates a revision of institutional routines.

In addition, public perceptions of probabilities and risks vary considerably from professional analysis (Slovic 1987; Covello 1983). Whereas experts usually give equal weight to probabilities and the corresponding magnitudes of a given risk, the intuitive risk perception places higher concern for low-probability, high-consequence risks than for high-probability, low-consequence risks, even if the expected values are identical. Thus risk communicators have to face the institutional problems of coping with the new challenge of stochastic reasoning and at the same time with the intrinsic conflict between the perspectives of the scientific community and the public in general. Both reasons justify the already established practice to isolate risk communication from other forms of communication and to treat it as a separate entity.

In spite of the legitimacy of risk communication as an independent subject of study, our literature review on this subject revealed a fair amount of ignorance or negligence in considering or applying the vast amount of research results from psychological or sociological studies on the effectiveness of communication and on the role of trust and credibility. Another shortcoming of the present risk communication literature is the sole focus on risk-related issues. The trend toward increased distrust in public institutions is a general phenomenon in modern societies so that risk communication has to be analyzed first in the context of organizational and institutional changes that have contributed to a more sceptical perception of organizational performance in general, before one focuses on the specifics of the risk arena.

This chapter summarizes the major findings of the psychological and sociological literature on trust and credibility, and applies these finding to risk communication. We will present preconditions for risk communication that 
are supported by the basic literature and that appear appropriate for the social and institutional context in which the risk debate takes place.

\section{A conceptual framework of trust and credibility}

Before presenting the major findings of scientific research on trust and credibility, some of the terms used in this chapter need to be explained. First, we begin by specifying what we mean by "risk communication." Then we discuss the various definitions of trust, confidence, and credibility. Finally, we introduce an analytical framework for studying trust in risk communication.

We adopt the definition of risk communication by Covello, von Winterfeldt and Slovic (1986) as "any purposeful exchange of information about health or environmental risks between interested parties" (see, however, the cautions by Kasperson and Stallen in the Introduction).

More specifically, risk communication is the act of conveying or transmitting information between parties about (a) levels of health or environmental risks; (b) the significance or meaning of health or environmental risks; or (c) decisions, actions, or policies aimed at managing or controlling health or environmental risks. Interested parties include government, agencies, corporations, and industry groups, unions, the media, scientists, professional organizations, public interest groups, and individual citizens (Covello, von Winterfeldt, and Slovic 1986: 172).

The definition limits the scope of risk communication topics to health and environmental aspects. This does not exclude the study of secondary and tertiary effects triggered by the communication process on health and environmental risks. On the contrary, the consequences of the communication effort in terms of psychological, social, and political repercussions are vital elements of the analysis of risk communication (Kasperson et al. 1988). The limitation refers to what is being communicated and not to the effects that the communication will have on social and psychological processes.

Since risk communication is defined as a purposeful exchange of information, we need a specification of the kind of intentions and goals that are associated with risk communication efforts. The literature offers different sets of objectives for risk communication, usually centered on a risk management agency as the communicator and groups of the public as target audiences. The list of objectives for entering a risk communication program includes the following items (cf. Covello et al. 1986; Zimmermann 1987; Kasperson and Palmlund 1987; Renn 1988): 
a) enlightenment function (to improve risk understanding among target groups);

b) right-to-know function (to disclose information about hazards to potential victims);

c) attitude change function (to legitimate risk related decisions, to improve the acceptance of a specific risk source, or to challenge such decisions and reject specific risk sources);

d) legitimation function (to explain and justify risk management routines and to enhance the trust in the competence and fairness of the management process);

e) risk reduction function (to enhance public protection through information about individual risk reduction measures);

f) behavioral change function (to encourage protective behavior or supportive actions toward the communicating agency);

g) emergency preparedness function (to provide guidelines for emergencies or behavioral advice during emergencies);

h) public involvement function (to educate decision makers about public concerns and perceptions);

i) participation function (to assist in reconciling conflicts about risk-related controversies.

The extensive list demonstrates the variety of goals and objectives that can be associated with risk communication programs. Increasing trust and credibility may be one major objective, but certainly is not the sole objective of risk communication. But many objectives, such as behavioral changes or fair participation, rely on a minimum of trust among the communicators in order to be effective.

Since trust is one major objective in risk communication and also a prerequisite for many other objectives, we need a better understanding of the meaning and implications of the term trust. If we consult the literature, we can find the following definitions (cf. Sheridan 1985):

a) "the confidence that one will find what is desired from another, rather than what is feared" (Deutsch 1973);

b) an "Actor's willingness to arrange and repose his or her activities on Other because of confidence that Other will provide expected gratifications" (Scanzoni 1979);

c) "a generalized expectancy held by an individual that the word, promise, oral or written statement of another individual or group can be relied on" (Rotter 1980);

d) "a generalized expectation related to the subjective probability an individu- 
al assigns to the occurrence of some set of future events" (Rempel, Holmes, and Zanna 1985);

e) "assured reliance on a person or thing" (Webster's Third International Dictionary).

Apparently all definitions emphasize the reliability of information and the conviction by the receiver that the source of a message has given truthful and complete information. For our purpose of defining trust in the context of communication, we suggest the following definition:

Trust in communication refers to the generalized expectancy that a message received is true and reliable and that the communicator demonstrates competence and honesty by conveying accurate, objective, and complete information.

Although trust and confidence are often used interchangeably, confidence in a source can be distinguished from trust as a more enduring experience of trustworthiness over time. Accordingly, confidence denotes the subjective expectation of receiving trustworthy information from a person or an institution. People have confidence in a source if their prior investment of trust in that source has not been disappointing over a longer period of time. If many persons share such a confidence in a communication source, they assign credibility to this source. So we can define credibility as the degree of shared and generalized confidence in a person or institution based on their perceived performance record of trustworthiness. All three terms imply a judgment of others about the quality of a message or a source. So they are all based on perceptions (Midden 1988). These perceptions, however, can be linked to special structural and performance characteristics of institutions.

To make these terms more operational, it makes sense to identify the major attributes that constitute trust, confidence, and credibility. The literature includes several approaches (Garfinkel 1967; McGuire 1985; Barber 1983; Lee 1986; Sheridan 1985). We decided to amalgamate some of the proposed suggestions from the literature and developed the following classification scheme.

Trust can be substructured in the following five components:

a) Perceived competence (degree of technical expertise assigned to a message or a source);

b) Objectivity (lack of biases in information as perceived by others);

c) Fairness (acknowledgement and adequate representation of all relevant points of view); 
d) Consistency (predictability of arguments and behavior based on past experience and previous communication efforts);

e) Faith (perception of "good will" in composing information).

Trust relies on all five components, but a lack of compliance in one attribute can be compensated by a surplus of goal attainment in another attribute. If objectivity or disinterestedness is impossible to accomplish, fairness of the message and faith in the good intention of the source may serve as substitutes. Competence may also be compensated by faith and vice versa. Consistency is not always essential in gaining trust, but persistent inconsistencies destroy the common expectations and role models for behavioral responses. Trust cannot evolve if social actors experience inconsistent responses from others in similar or even identical situations.

Confidence is based on a good past record of trust-building communication. In addition, the performance of the source and its image with respect to its fulfilment of tasks and communicative functions are major attributes that constitute confidence. High social support for a source can serve as a reinforcement for generating and sustaining confidence. In addition, congruence of its goals and values with those of the targeted audience may enhance confidence (Luhmann 1973).

Both trust and confidence are necessary conditions for the assignment of credibility to a source. Credibility is a product of long-term evidence and commonly shared experience that a source is competent, fair, flexible to new demands, and consistent in its task performance and communication efforts. Judgments about these criteria are based on social perceptions. These perceptions, however, are at least partially governed by structural factors, such as the success or failure in meeting the socially assigned roles and expectations and the institutional openness for public demands and requests. Thus, it makes sense to distinguish between genuine perception factors (image aspects) and structural factors (characteristics or properties of institutions that affect the social perceptions). All three-trust, confidence, and credibility-are also subject to the macro-sociological climate in a society vis-a-vis social institutions and their role for social cohesion (Lipset and Schneider 1983). This influence is independent from the actual performance or communication record of the source.

For analytical purposes it seems appropriate to differentiate between different levels of trust, confidence, and credibility, depending on the source and the situation. We developed, therefore, a classification scheme that is composed of five distinctive levels of analysis: trust in a message, confidence in a communicator, confidence in an institution based on source perception, credibility of 


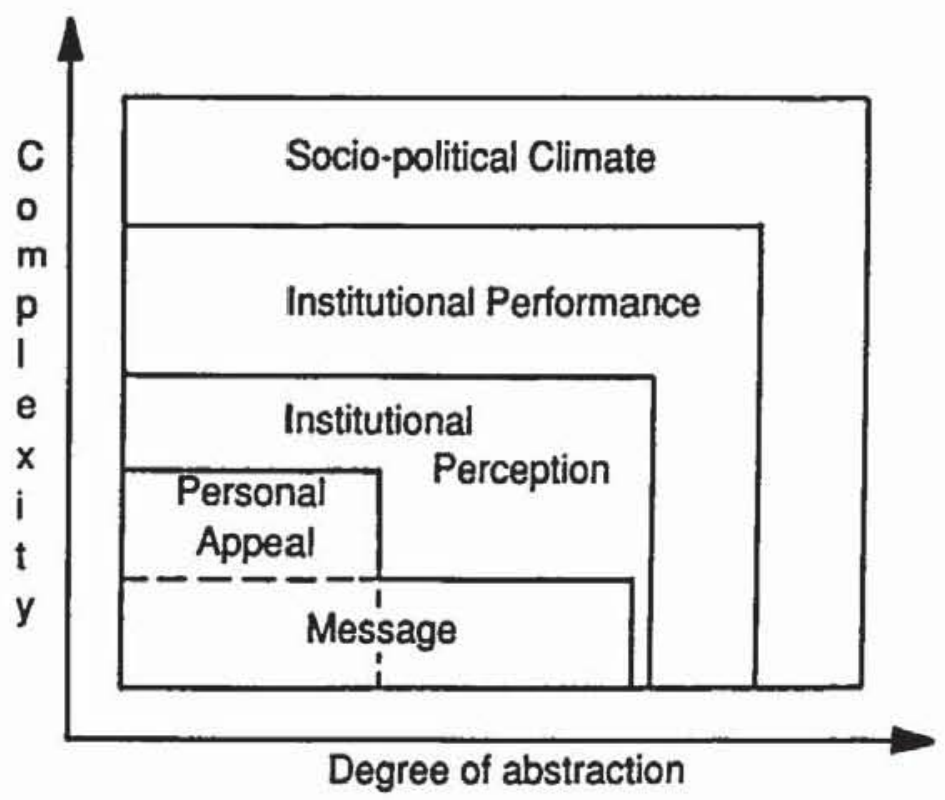

Fig. 9.1. The five levels of analyzing trust.

institutions based on institutional performance, and climate for trust and credibility in a macro-sociological context.

Figure 9.1 illustrates the cumulative nature of these five levels. The figure is a simple illustration of the interrelations among the five levels. Each level is embedded in the next higher level. Consistent violation of trust-building efforts on one of the lower levels will eventually impact the next higher level. Distrust on a high level sets the conditions and determines the latitude of options for gaining or sustaining trust on a lower level. The order of levels is also associated with an ascending order of complexity and abstraction. It is therefore easier to predict how changes in communication may affect trust on the lower levels compared to changes on the higher levels. But the circumstances prevalent in the higher levels operate as constraints on any effort to improve trust on a lower level.

The levels of analysis enable us to identify the elements within each level that may contribute to trust, confidence, or credibility. Table 9.1 illustrates the key variables in each of the levels and shows their interrelatedness. The "message" rubric includes all the variables that influence the perception of competence, fairness, consistency, and faith. Personal variables, such as appearance, appeal, style, and responsiveness, affect the trust and confidence that a person conveys to his or her audience. Furthermore, institutional performance and image color the acceptance and evaluation of a message and influence the reception of the communicator by the targeted audience. All variables that we identified as relevant on this level are summarized in the two rubrics representing image and performance of institutions. Last, the social 
Table 9.1. Factors of credibility for different levels of analysis.

MESSAGE:

Positive:

Timely disclosure of relevant information ${ }^{1}$

Regular updating with accurate information ${ }^{1}$

Clear and concise ${ }^{1}$

Unbiased $^{3}$

Sensitive to values, fears and concerns of public ${ }^{4.5}$

Admits uncertainty ${ }^{1}$

From a legitimate reputable source $\mathrm{e}^{3.4}$

Organized messages

Use of metaphors

Explicit conclusions 5

Positive information recorded in early part of message ${ }^{5}$

Forceful and intense ${ }^{6}$
Negative:

Stalled or delayed reporting ${ }^{1}$

Inconsistent updating

Full of Jargon ${ }^{2}$

Biased $^{3}$

Inconsiderate of public perception ${ }^{3}$

The absolute truth

From a questionable source

Too literal ${ }^{5}$

Receiver derive own conclusion ${ }^{5}$

Dull $^{6}$

\section{PERSON}

Positive:

Admits uncertainty ${ }^{1,3}$

Responds to emotions of public ${ }^{3}$

Appears competent ${ }^{1,6}$

Similarity with receiver, ${ }^{5,6}$

Has some personal stake in the issue ${ }^{3}$

Clear and concise ${ }^{1}$

Perceived as "expert"

Perceived as "attractive"s

Charismatic $^{3}$

Trustworthy-honest, altruistic, and objective ${ }^{6}$
Negative:

Cockiness

Indifference

Perceived as outsider ${ }^{3}$

Too technical ${ }^{2}$

\section{INSTITUTIONS:}

a) abstract

Positive:

Healthy economy, low inflation, unemployment ${ }^{7}$

New administration, new ideas?

Period of relative tranquility ${ }^{7}$

Perception of competent leadership 7

Perception of altruistic motivation ${ }^{7.8 .9}$

Peace $^{7}$

b) concrete

Positive:

Positive personal experience ${ }^{7}$

Strong, competent leadership ${ }^{7}$
Negative:

Recession?

High inflation, high unemployment ${ }^{7}$

Corruption?

Domestic violence or unrest ${ }^{7}$

Poor leadership ${ }^{7}$

Image of self-serving motivation ${ }^{7.89}$

$\mathrm{War}^{7}$

Negative:

Negative personal experience ${ }^{7}$

Incompetent? 
Table 9.1. (continued)

Positive P.R. ${ }^{7}$

Sound environmental policy?

Produces safe and good/service?

Positive past record of performance?

Reasonable rates ${ }^{8}$

Undertakes socially relevant tasks

Practical contributions to every day life ${ }^{10}$

Benefits outweigh costs"
Layoffs/hiring freeze strikes?

Irresponsible environmental policy

Poor quality goods/services?

Negative past record of performance?

Exhorbitant prices ${ }^{8}$

Magnitude of risk taking greater than benefits ${ }^{11}$

\section{POLITICALCULTURAL CONTEXT}

\section{Positive:}

Faith in institutional structures?

Checks and balance system functioning well ${ }^{7}$

New and innovative ideas?

\author{
Negative: \\ Perception of structural decline? \\ Poor leadership/incompetence ${ }^{7}$ \\ Corruption/scandall \\ Energy crisis \\ Perception of unfair taxation
}

Perception of worsening financial

situation ${ }^{7}$

Social unrest ${ }^{7}$

Terrorism ${ }^{7}$

${ }^{1}$ New Jersey Department of Environmental Protection, Division of Science and Research, Improving Dialogue with Communities. By Billie Jo Hance, Caron Chess, and Peter Sandman. January 1988.

2 Parker, Laura. "Safety Board Hearings Focusing Public Attention Rather than Solving Crisis." Washington Post, July 29, 1988.

${ }^{3}$ Gricar, Barbara GH, and Anthony J. Baratta. "Bridging the Information Gap at Three Mile Island: Radiation Monitoring by Citizens." J. Applied Behavioral Science. Vol. 19, 1983.

4 Anderson, Craig. "Abstract and Concrete Data in the Perseverance of Social Theories: When Weak Data Lead to Unshakeable Beliefs. J. Experimental Social Psychology 19, 93-108 (1983).

s Lee, Terrence. "Effective Communication of Information About Chemical Hazards." The Science of the Total Environment 51 (1986): 149-183.

${ }^{6}$ Covello, Vincent T, Paul Slovic, and Detlof von Winterfeldt. Risk Communication a Review of the Literature, Draft. July 1987.

${ }^{7}$ Lipset, Seymour M. and William Schneider. The Confidence Gap; Business, Labor, and Government, in the Public Mind. New York, The Free Press. 1983.

${ }^{8}$ Burnham, John C. “American Medicines's Golden Age: What Happened to It?" Science. Volume 215, 19 March 1982.

' La Porte, Todd R and Daniel Metlay. Technology Observed: Attitudes of a Wary Public.“ Science, Volume 188, 11, April 1975.

${ }^{10}$ Pion Georgine M. and Mark W. Lipsey. "Public Attitudes Toward Science and Technology: What Have the Surveys Told Us?" Public Opinion Quarterly, Vol. 45: 303-316, 1981.

"Slovic, Paul et al. "Perception and Acceptability of Risk from Energy Systems." In Advances in Environmental Psychology, Vol. 3, Energy: Psychological Perspectives. A. Baum \& J. E. Singer (Eds). Hillsdale, New Jersey, Erlbaum, 1981. 
political climate shapes the readiness of receivers to give credit in terms of prior confidence to a communicator. In times of predominant distrust in institutions, the expectation that communicators are trying to deceive their audience is the default option in receivers' attitudes toward a communication source. Under such conditions, active trust management is certainly required. In times of a positive climate of confidence in institutions, trust is given as an initial investment or credit to new sources but may easily be lost if abused.

\section{Insights from psychological studies}

Trust as prerequisite for social orientation. Interaction among individuals relies on a minimum of trust between the actors involved, at least to the point that they share a common meaning of the elements of the communication process. Thus trust is a prerequisite for any social interaction and is, at the same time, a major mechanism to provide orientation in uncertain situations. It also makes the outcome of a communication more predictable. In this sense, trust is a medium to reduce complexity by limiting the scope of behavioral responses. But it is also a medium to enhance complexity because it entails a higher degree of freedom for behavioral actions without implying an extensive debate between the interaction partners about the legitimation or appropriateness of each other's actions (Barber 1983; Luhmann 1980).

The knowledge concerning the functions of trust in social interactions does not answer the question of how to establish trust in the first place and how to regain trust if the respective audience feels that the credibility of a communicator is weak or even non-existent. For risk communication in particular, it is important to know what kind of conditions and behavioral approaches are more likely to create an atmosphere of mutual trust among the communication partners. As we outlined above, components such as competence, objectivity, neutrality, and faith are major building blocks for creating a trustful relationship.

Psychological research about attitude and attitude change has shed some light on the conditions under which receivers of information assign trust or one of its building blocks, such as competence, to a communicator. These research results are usually discussed in the framework of persuasion: What elements of a message or a communication context are likely to enhance or diminish the persuasive effect of a message? What elements of the message are remembered and which trigger changes in opinions or attitudes?

Before reporting on some results of these studies, we should mention the restrictions and limitations of these studies to avoid misinterpretation (McGuire 1985; Anderson 1983; Meinefeld 1977). Most of the research in 
attitude change has been performed in laboratory settings with student populations. Most experiments were done with a limited set of issues or topics so that it is not clear whether the revealed relationships can be extended to other topics or audiences. Many experiments were conducted in the 1950 s and 1960 s, both time periods in which the social climate for trust and credibility differed considerably from today's climate. For example, experiments involving experts as communicators resulted usually in considerable persuasion effects in the early 1960 s whereas more recent experiments demonstrate more ambiguous results depending on the existence of a social controversy over the issue and the social perception of the expert's own interests (Eagly et al. 1981; Heesacker, Petty and Cacioppo 1983). But at the same time many of the research findings are consistent over long time periods and have been tested with a variety of subjects and topics (Chaiken and Stangor 1986; Eagly and Chaiken 1984). So they can be regarded at least as well founded hypotheses for application in risk communication until more specific research studies are conducted.

Psychological insights from persuasion experiments. The following review of research results is based on psychological experiments on persuasion. For the purpose of this chapter, we will only present the conclusions and omit the methodology or design of these studies. Readers interested in a more detailed review should consult the respective review articles (McGuire 1985; Chaiken and Stangor 1987; Eagly and Chaiken 1984; and specifically for risk communication Lee 1986). Among the factors that have been found to enhance the persuasiveness of a communication are:

- Attractiveness of information source: attractiveness is composed of similarity of positions between source and receiver; likability of source; and physical attraction (Lee 1986; McGuire 1985; Chaiken and Stangor 1987).

- Sympathy or empathy of the receiver with the source: this refers to the possibility of a receiver to identify with the source or its motivations (McGuire 1985; Eagly and Chaiken 1984).

- Credibility of source: among the components tested are perceived competence, expertise, objectivity, impartiality, and fairness (Lee 1987; Tyler 1984; Rempel and Holmes 1986).

- Suspicion of honest motives: receivers do not detect any hidden agendas or motives behind the communication effort (Rosnov and Robinson 1967; Eagly et al. 1981).

- High social status or power of communication source: the effect of these two variables depend heavily on the issue and the composition of the audience (McGuire 1985; Chaiken and Stangor 1987; Lee 1986). 
These factors seem almost intuitively plausible. A communicator is likely to leave a more lasting impression on the audience if the message appears honest, accurate, and fair and if the communicator is a likable person with whom the audience can easily identify. The more difficult question, however, is how a communicator can accomplish to impart these impressions on the audience under real life conditions. What do we know about the effectiveness of message composition and personal appeal that would allow us to tailor information programs to seek more persuasive power?

(Un)fortunately, we do not have any recipes to enhance credibility or to increase the persuasiveness of a message. But psychological research in the past two decades has yielded some interesting, sometimes even counterintuitive, findings that link specific aspects of message composition or personal style of communication with persuasive effect. These findings are summarized in Table 9.1 under the two rubrics of "message" and "personal factors". Some of the more counter-intuitive factors deserve special mentioning:

a) High credibility sources, such as scientists or opinion leaders, produce more opinion change, but no difference in message learning compared to other sources. The learning of a message is more related to the similarity of the message than to existing attitudes and beliefs (Hovland and Weiss 1967; McGuire 1985).

b) Perceived expertise depends on many factors. Among them are status, education, perception of technical authority, age, and social class. If expertise of a communicator is challenged in public, people tend to focus on substitutes for expertise, such as suspected interests or reliance on reference group judgments (Heesacker et al. 1983; Renn 1984).

c) Stating explicitly the persuasive intent is usually more convincing than hiding such an intent and leaving it to the audience to make their own inferences. People like to know what the communicator wants them to believe. If it is not openly stated, they will suspect a hidden agenda (Lee 1986; McGuire 1985).

d) Perceived fairness and social status are both variables that can compensate lack of objectivity. Even if people are aware that the communicator has a vested interest in the issue and that $\mathrm{s} / \mathrm{he}$ argues from a specific viewpoint, they may trust the message or develop confidence in the communicator provided that the information presented appears to be fair to potential counter-arguments and that it is presented with technical authority (Lee 1986; McGuire 1985).

e) Being explicit in conclusions and presenting counter-arguments to potential objections have been proven more effective than operating with implicit conclusions or presenting only one side of the story. The two often conflict- 
ing goals of fairness to the opponent's view and of honesty about one's own motives have to be reconciled in each communication effort in order to be most persuasive (Lee 1986; McGuire 1985).

f) The perception that the goals and motives of the source serve a common interest or refer to highly esteemed social values, such as protection of the environment or public health, enhances public confidence in the communicator but reinforces distrust if the task performance of the communicator is perceived as weak. People invest more trust in these institutions in the beginning, but tend to be more disappointed if the outcome does not match their expectations (Tetlock 1986).

g) The agreement to listen to disliked sources increases the probability of attitude change. Although likableness of a source usually enhances the persuasive effect, the mere acceptance of listening to a non-likable source may motivate the audience to focus on the message instead of the source of communication. The psychological mechanism involved here is called avoidance of cognitive dissonance (Festinger 1957). One can only justify spending time with a disliked source if at least the message is worth the effort. However, the motivation to engage in communication with a disliked person may also serve as a reassurance of how bad the source and the message are. Which of the two reactions is likely to emerge as a result of a communication with a disliked source? This depends on the degree of commitment to one's previous attitude, the strength and salience of the attitude with respect to other beliefs and values, and the perception of vested interests of the source (Fazio et al. 1977; Chaiken and Stangor 1987).

All these insights are helpful to design communication programs and to train communicators for their task. But it should be kept in mind that most of these results were accomplished in rather artificial laboratory environments and may not be valid for the specific risk communication arena. Risk communicators who are familiar with the persuasion literature have assured us, however, that many of the findings from persuasion research match very well their personal experience with risk communication. So these studies provide some helpful clues of how to design a more effective communication program and may serve as a starting point to conduct more specific research projects on trust in risk communication.

The elaboration-likelihood model and its application to trust and credibility in risk communication. So far we presented a review of functional or causal relations between characteristics of communication and their effects on persuasiveness. The reported results were deliberately isolated from the theoretical context in which they are embedded. Our intent was to demonstrate the 
instrumental value of these studies for analyzing and designing communication programs, without referring to complex psychological models or theories. Given the vast amount of potential candidates for such a theoretical framework, we had to make a deliberate selection and to choose a model that we feel is most appropriate for risk communication. Our preferred choice is the "elaboration-likelihood model of persuasion," developed by Petty and Cacioppo in the late 1970s (overview in Petty and Cacioppo 1986). In spite of its recent appearance, this model has been extensively reviewed by social psychologists and has received many favorable comments (Chaiken and Stangor 1987; Eagly and Chaiken 1984). In addition, C. Midden has explicitly recommended this model for application in risk communication (Midden 1988).

The major component of the model is the distinction between the central or peripheral route of persuasion. The central route refers to a communication process in which the receiver examines each argument carefully and balances the pros and cons in order to form a well-structured attitude. The peripheral route refers to a faster and less laborious strategy to form an attitude by using specific cues or simple heuristics (cf. Fig. 9.2). When is a receiver likely to take the central route and when the peripheral route? According to the two authors, route selection depends on two factors: ability and motivation. Ability refers to the physical capability and opportunity of the receiver to follow the message without distraction, motivation to the readiness and interest of the receiver to process the message. Three conditions have to be met to satisfy the criterion of ability: the information has to be accessible, the receiver must have the time to process the information, and other sources of distraction should be absent.

Several factors influence the motivation of a receiver to process actively the information. The information content has to be relevant (referring to personal interests, salient values, or self-esteem) and it should trigger personal involvement (with the issue, the content, or the source). Both motivational factors are reinforced if the receiver has some prior knowledge or academic interest in the subject or is in need of new arguments to back up his pre-formed point of view. The model would also suggest that high-ego involvement (i.e., the match between message content and the recipient's functional or schematic predispositions) increases the likelihood that the central route is taken. Such a preference for a route, however, does not provide an indication about the success of the persuasion attempt. It rather demonstrates that the receiver will engage in a systematic processing of the information. But this process may tend to be biased in favor of the subject's initial attitudes (Chaiken and Stangor 1987).

The peripheral route is taken when the issue is less relevant for the receiver and/or the communication context is inadequate to get the message across. In 


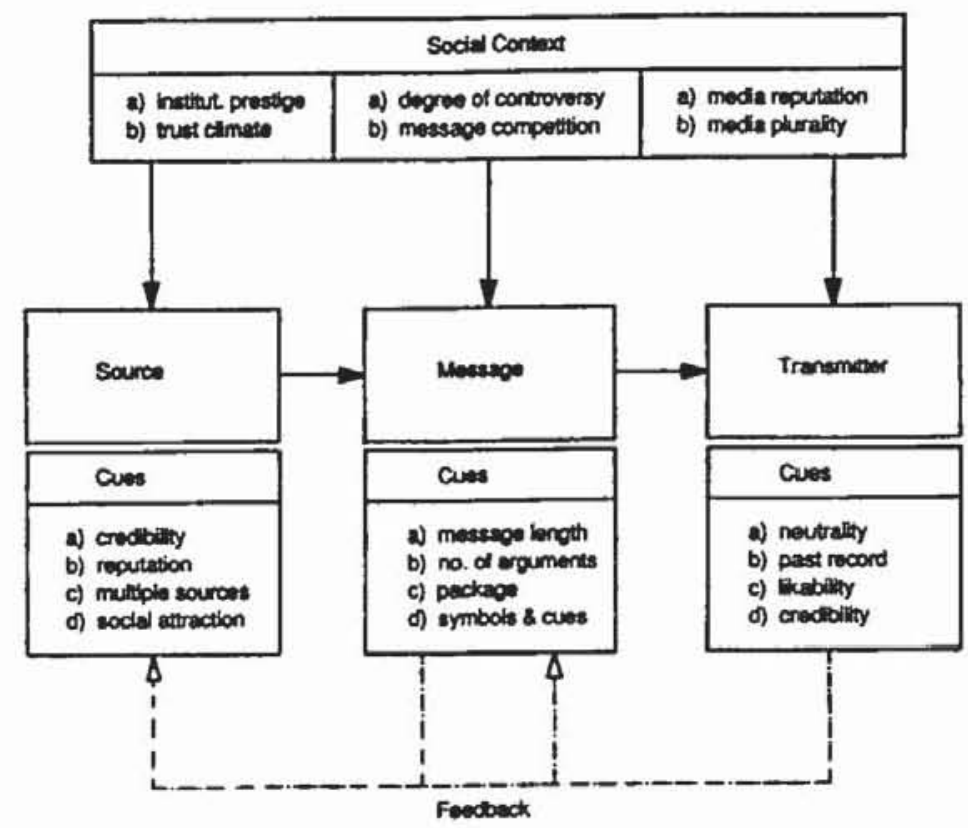

Fig. 9.2. Heuristic cues of persuasion in communication

this case, the receiver is less inclined to deal with each argument, but forms an opinion or even an attitude on the basis of simple cues and heuristics. In Fig. 9.2 we order these peripheral cues in the framework of the simple sourcereceiver model (Shannon and Weaver 1949). We classified the cues into four categories: source-related, message-related, transmitter-related, and contextrelated cues. With respect to the source, aspects such as credibility, reputation, and social attractiveness are important cues for receivers to adopt a specific message. It also helps to have the message sponsored by multiple sources (Midden 1988). The message factors include the length of a message, the number of arguments, the package (color, paper, graphic appeal, and others), and the presence of symbolic signals that trigger immediate emotional responses (cf. Kasperson et al. 1988). The transmitter of a message may also serve as carrier for specific cues: the perceived neutrality, the personal satisfaction with the transmitter in the past (this magazine is always right), the similarity with the political or ideological position of the transmitter, and the social credibility assigned to a transmitter are used to form an opinion or attitude. In addition, specific channel-related aspects, such as visual impressions from the TV screen, are readily accessible cues in this route of persuasion.

Social context variables that serve as peripheral cues are often neglected in the discussion of the peripheral route. The social climate for trust and credibility and the image of institutions in a society may create a specific predisposition to accept or reject the arguments of a source. With respect to the risk arena, 


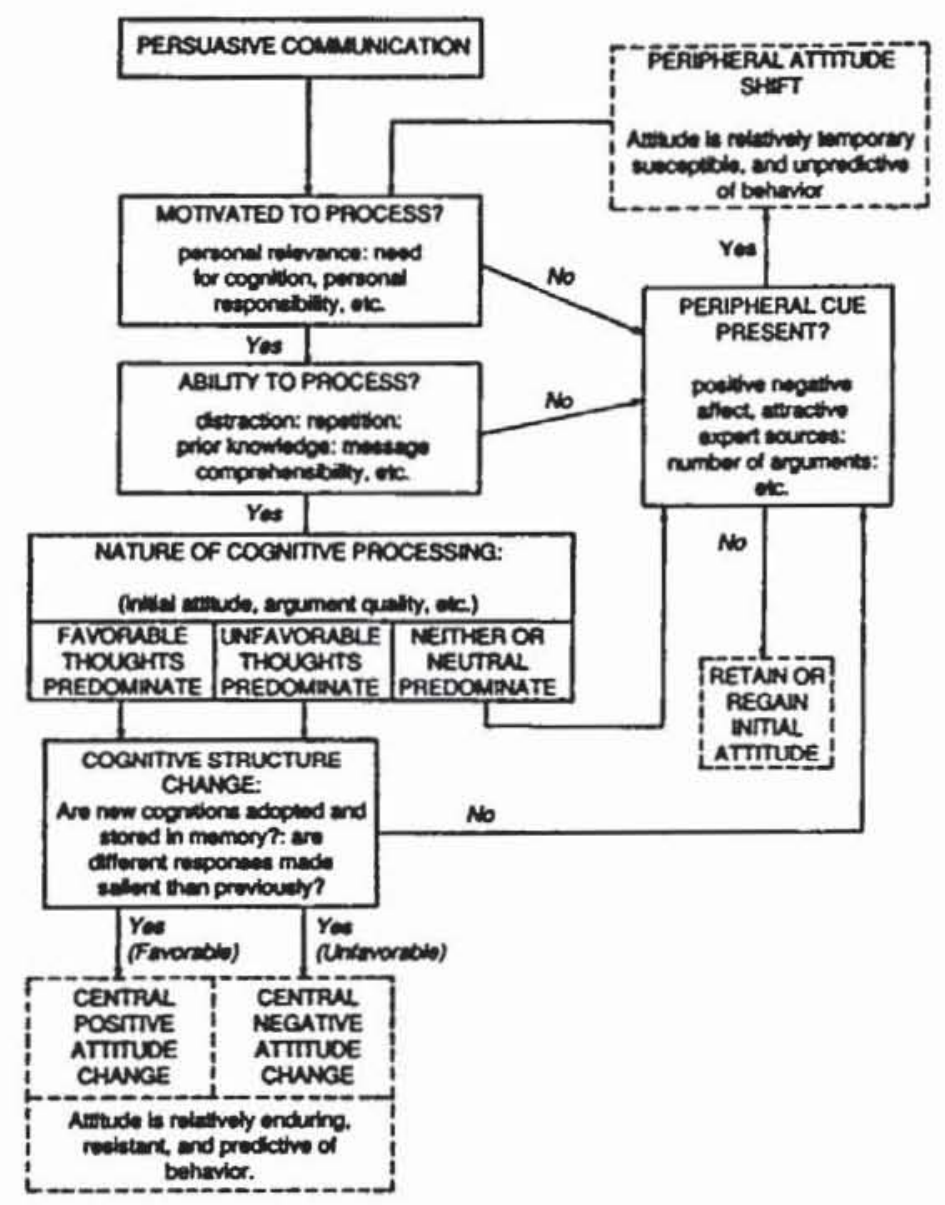

Fig. 9.3. Elaboration likelihood model of persuasion (Petty and Cacioppo 1986).

the dominant impression of expert controversy and the presence of competing messages have already been identified as significant cues that initiate a sceptical or at least cautious reception mode (Slovic 1987). Other variables can be added to this category, as, for example, the plurality of transmitters or the social reputation of specific media.

Within each route, the mental process of forming an attitude follows a different procedure. Figure 9.3 illustrates the original model by Petty and Cacioppo. The central route is characterized by a systematic procedure of selecting arguments, evaluating their content, balancing the pros and cons, and forming an attitude. The peripheral route, however, bypasses the systematic approach and assigns credibility to a message by referring to the presence of cues.

Unfortunately, the communication process is more complex than the model in Fig. 9.3 implies. First, the audience of a communicator may be mixed and consists of persons with central and peripheral interests in the subject. Many cues that are deliberately used to stir peripheral interest (e.g., using ad- 
vertising methods for risk communication) can be offensive for people with a central interest in the subjects. Second, most people are not predisposed to exercise a central or peripheral interest in a subject. Rather it may depend on the message itself whether it can trigger central interest or not. Third, and most important, the two routes are prototypes of attitude formation and change, and therefore only analytically separable. In reality, the two routes are intertwined: persons may tend to respond primarily to the cues or primarily to the arguments presented, but they will not exclusively pursue one route or the other.

The two authors of the elaboration-likelihood model have emphasized the interrelatedness of the two routes. Other authors, such as Eagly and Chaiken (1984) or Eagly et al. (1981), have proposed intermediate routes that are not based on arguments or cues but on attributional reasoning. The arguments here are evaluated according to the plausible reasons for a communicator's stated position on an issue. Such an approach is less demanding than issuerelevant thinking, but more demanding than heuristic processes (Chaiken and Stangor 1987).

Development of a multistage model of persuasion. Inspired by the elaborationlikelihood model and based on our previous work on modelling stages of attitude formation (Renn 1984), we developed a modified version of the persuasion model. This model is less specific in terms of identifying the factors that lead either to a central or peripheral route of information reception, but more elaborate with respect to the different sequential stages in selecting, assimilating, and evaluating information. The major thrust of our model is the simultaneous presence of central and peripheral elements in the different stages of attitude formation.

Figures 9.4 and 9.5 illustrate our model of attitude formation or change. The left column describes the sequential steps of attitude formation starting with the reception of a message and ending with the post-rationalization of the beliefs (the cognitive components of an attitude). This multi-step decomposition of the attitude formation process is based on attitude theories by Rokeach (1969) and Fishbein and Ajzen (1975) and was developed and graphically displayed in Renn (1984). The right column lists the factors that influence each stage of this process and that determine whether the attitude formation process is terminated prematurely. It also shows what further route is selected. In concordance with the elaboration-likelihood model, we differentiated two routes of persuasion: a central and a peripheral route. But both routes are identical in the first three stages of our model and both comprise a mixture of issue-related aspects and peripheral cues. The major difference between the two lies in evaluation. While the central route requires a processing of each 


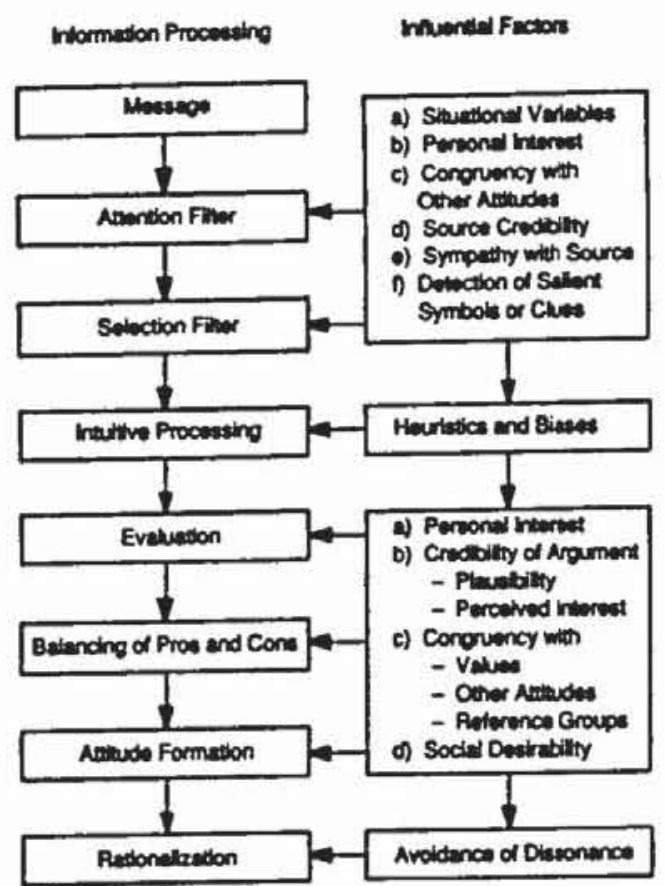

Fig. 9.4. The central route of persuasion.

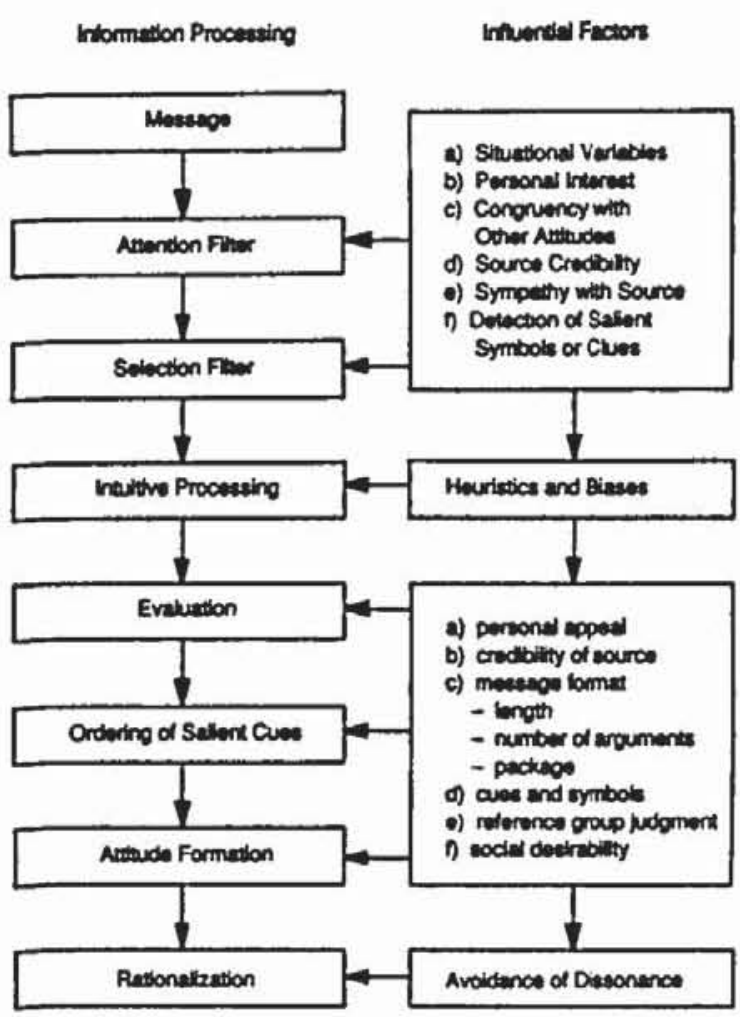

Fig. 9.5. The peripheral route of persuasion. 
argument according to a number of evaluative factors (including peripheral cues), the peripheral route relies predominantly of non-issue related cues in the evaluation of the information. Consequently, the central route includes a step of balancing pros and cons; the peripheral route, by contrast, involves only an ordering of cues to form a compound judgment.

The first three stages that are identical for both routes of persuasion refer to the process of becoming aware of the information (attention filters), selecting the relevant parts of the information, and processing its cognitive content. The recipient will decide during these three stages whether the issue is of central interest to him/her and whether s/he will terminate the further processing of the information. If the interest is low and other compensatory cues are missing, then the person is likely to reject the information. Medium interest or the presence of specific cues will initiate a peripheral route to establish an attitude. High interest and the presence of many reinforcing cues are likely to produce enough involvement for a recipient to choose the central route. The important factor here is that both routes, the central and the peripheral one, are dominated by peripheral cues in the early process of attitude formation. Furthermore, the initial selection of information from the message is highly governed by the person's predispositions and a special set of peripheral cues, such as novelty of the information, the mentioning of prestigious persons or institutions, or specific symbolic keywords or signals (Slovic 1987; Cotton 1985; Frey 1986).

The third step of intuitive processing of cognitive information refers to the heuristics and common sense mechanisms of drawing inferences from the information presented. The rich literature on heuristics and biases in processing information provides no indication of different strategies for persons with low or high issue involvement (Tversky and Kahneman 1975; Jungermann 1982; Jungermann and May 1988). Attribution biases, such as availability, anchoring effect, or representativeness, are common processes for all routes of attitude formation. Although one cannot classify these heuristics as peripheral cues, they are still representations of simple rules to cope with complex information. In the peripheral route, these cognitive heuristics may be replaced partially by even simpler cues like credibility of the source, but if cognitive information is processed at all, these heuristics will govern the intuitive generalization process regardless what route of information processing is pursued.

The major difference between the peripheral and the central route lies in the process of evaluation, the fourth step of our attitude model. In the central mode, the receiver performs two types of evaluations: first, an assessment of the probability that each argument is true, and second, an assignment of weight to each argument according to the personal salience of the argument's 
content. Both tasks are usually performed holistically, but any balancing act requires these two inputs (cf. the attitude model by Fishbein and Ajzen 1975).

The credibility of each argument can be tested by referring to personal experience, plausibility, and perceived motives of the communicator. In modern societies with highly professionalized and differentiated knowledge, experience and plausibility are often weak instruments to evaluate the truth of a statement (Renn 1986). No lay person, for example, has any evidence to prove or disprove an expert's claim that low radiation causes cancer. Rather recipients use secondary cues, such as prestige of the source, suspicion of vested interests, or judgments of reference groups to evaluate the accuracy of a statement (Eagly et al. 1981; Heesacker et al. 1983). It is important to note that in these instances, where personal experience is lacking, both the central and the peripheral route are almost identical because they rely on judgment of trust or credibility. While this judgment is made for each argument in the case of the central route, it is made for the total message or holistically for the source in the case of the peripheral route.

The evaluation of the salience of each argument is performed by a comparison of the message with one's personal interests, one's own value system, other major attitude and beliefs, and the perceived social desirability of the intent of the message (Chaiken and Stangor 1987; Renn 1984). This process may be more or less pronounced and not all comparisons have to be made for each argument. But the major incentives for changing an attitude in the central mode are the proximity with and the affinity to one's own interests, values, world views, or socially accepted or internalized norms. In the peripheral mode, receivers do not bother to deal with each argument separately, but look for easily accessible cues to make their judgment.

The last two stages refer to attitude formation and rationalization. After the formation process in which the receiver incorporates the message into his/her attitude system, the potential negative arguments are frequently suppressed or re-directed into a positive view. This is done more intensely if the balancing act created more pain. This process of bolstering helps to avoid cognitive dissonance and post-decisional regret. Both routes do not differ in these last two stages.

How can this model be helpful for analyzing and designing risk communication programs? First, it points out that credibility and trust are not only relevant factors in the peripheral route of persuasion, but also in the central route. The perception of credibility is a major component of the attention and selection filter and, at the same time, a heuristic tool to assess the probability that an argument is indeed accurate and valid. Functional equivalents are available in both cases, but specifically for issues in which personal experience 
and intuitive plausibility are lacking, trust in the communicator plays a major role.

Second, an effective risk communication program must contain a sufficient amount of peripheral cues to initiate interest in the message, but also enough "rational" argumentation to satisfy the audience with central interest in the subject. The problem is how to avoid anger and rejection by centrally interested persons if they are confronted with "superficial" cues, such as advertising gimmicks, and how to sustain the interest of the peripherally interested persons if they are confronted with lengthy argumentation. The problem can be resolved if the message avoids to include "obvious" cues, but relies on cues that are acceptable for both audiences, the centrally and the peripherally interested persons.

Third, the complexity and multitude of influential factors that govern attitude formation make it impossible to design fool-proof recipes for influencing (or even worse: manipulating) people. Internal values, the perception of own interests, external pressures, and role-models, as well as personal experience, are the most powerful agents in attitude formation. The design and packaging of the message may help to make people aware of the message and to appear at least more credible. But the desired effect of changing people's attitudes or opinions will occur only if the powerful evaluation agents on which the communicator has hardly any influence are already directed in favor of the message.

\section{Sociological factors of trust and credibility}

Trust in sociological perspective. For this discussion, we adopt a broader perspective and analyze the role that credibility and trust play in the context of social structures and processes. Beyond the individual judgment of assigning trustworthiness to a source of information, confidence in the institutional management of social tasks and trust in the communication between subsystems of society constitute aggregate conditions that determine the overall climate of trust in a society. They are related to the perceived performance of institutions and their flexibility to cope with new demands.

Trust on a personal level is a subjective expection that a person will refrain from behavioral options that may harm the trusting person. Above we translate this general concept of trust into the communication context. Trust necessarily entails risk-taking, but, in contrast to the scientific endeavor of predicting the probability of potential outcomes, trust implies that the selection of options is left to the entrusted person or institution. Due to the 
perceived competence and honesty of the entrusted entity, one does not need to bother with assessing the outcomes of actions and with controlling the decision making process of that entity (Luhmann 1980,1973). This saves time and effort.

On a more aggregate level, trust denotes a generalized medium of social differentiation and division of labor (Parsons 1960). The performance of specialized institutions in economy and government relies on a prior investment of trust by those who are served by this institution or finance its functioning. Total control would imply that the control agencies would need the same expertise and the same time allocation as the performing institution. Such an arrangement would neutralize the desired effect of social differentiation and ultimately lead to a society of intimate clans performing all necessary social, economic, and political functions simultaneously. Such an intimate framework based on familiarity with each individual in the clan may be able to operate within a closed egalitarian community (cf. the group-grid distinction in anthropology; cf. Thompson 1983), but a modern, functionallydivided society could not function without trust as a general medium of social communication.

By shortcutting normal control mechanisms, trust, and later on confidence (based on positive experience with granting trust to a specific social actor), can be a powerful agent for efficient and economical performance of social tasks. Durkheim's analysis of organic solidarity as a major structural variable of modern societies focused on trust as one of the predominant media that helped to shape the division of labor and to differentiate societal functions (Durkheim 1933; Luhmann 1973).

Trust as a generalized medium is characterized by a diffuse and unspecified relationship between the involved actors (Parsons 1960; Parsons and Shils 1951). Similar to another generalized medium, such as money or prestige, its existence and functioning is independent of individual consent. But it can inflate or deflate as a result of the commonly expressed "trust in trust" (Luhmann 1973). The relative value of trust varies over time, as empirical surveys clearly indicate (Lipset and Schneider 1983). In some periods, people tend to invest a large amount of trust in institutions and it takes many disappointments before they withdraw this investment. In other periods, people tend to be extremely cautious with the investment of trust, placing more emphasis on functional equivalents, such as more organized control or increase of participation. Trust can partially be substituted by other generalized media, but not totally replaced.

As we focus on trust in communication, we are interested only in the ways that the general climate of trust and the structural performance of institutions set the stage for confidence in communication sources and their credibility. 
The assignment of credibility is obviously related to the perception of the past performance of the communicator. This record does not include only the experiences of the audience with earlier communication efforts, but also their evaluation of the institutional task performance. If an institution does not meet the demands of the public, they are likely to face a credibility crisis even if they are absolutely honest about their failures. Specifically, risk communication is regarded as trustworthy only if the communicator is able to convey the message that $\mathrm{s} /$ he has met the public expectations in managing risks. Risk management and risk communication are closely linked, and a bad management record cannot be compensated by an excellent communication effort. Communication may help to change public expectations or to correct misperceptions of the actual record, but it will not cover the gaps between expectations and perceived performance.

In the discussion to follow, we investigate first the effect of institutional performance and institutional structure on perceived credibility and then introduce a model for structuring risk debates based on the sociological concept of knowledge. Our goal is to identify the elements and processes that are likely to increase or decrease trust in communicators.

Trust and institutional performance. In analogy to the description of research results in psychological experiments, we turn to some of the interesting findings of sociological and organizational research with respect to trust and credibility of institutions. In contrast to the laboratory experiments in psychology, these findings are derived from surveys and other statistical data. On one hand, they are more applicable to "real" world situations; on the other hand, they involve verbal reflections of respondents in surveys and may be influenced by other factors than the proposed verbal stimulus. In addition, survey results leave more room for subjective interpretation of data than laboratory results. Caution is also advised in translating these results from the arena in which they were observed to the arena of risk management.

Again we will focus on the results of various studies and omit the description of the methodology and their specific design. For a more detailed review, the reader should consult the respective literature (e.g., Lipset and Schneider 1983; Rourke et al. 1976; Katz et al. 1975):

a) Researchers found a low correlation between the perception of institutional competence and the desirability of the tasks and goals that the institutions were performing. The institutions people like most received low ratings on competence and vice versa. Although sympathy helps to attain credibility, perceived competence alone may be sufficient for gaining trust. But the lack of sympathy makes people more critical towards the actual perform- 
ance of the institution. Mistakes are more likely to be forgiven if the communicator can count on a sympathetic audience (Lipset and Schneider 1983).

b) Perceived competence of institutions was most likely associated with the perception of a successful task performance and the perceived cost-benefit ratio in meeting these tasks. In addition, the public image and the social prestige assigned to an institution serve as preliminary heuristic strategies to assign credibility (Matejko 1988).

c) Perceived fairness and openness, the second prerequisite for institutional credibility, is closely linked to the transparency of the decision making process, the opportunities for public scrutiny and institutional control (check and balances), and the degree of personal satisfaction with the rationale and procedures for decision making in the respective institution. Surprisingly, the amount of actual opportunities for public involvement and participation was hardly correlated to perceived openness (Lipset and Schneider 1983; cf. theoretical concept Luhmann 1980).

d) Institutional case studies demonstrated that the erosion of credibility was often linked to: incompetence, poor performance, incomplete or dishonest information, withholding of information, obscure and hidden decision making processes, denial of obvious problems, and denial of vested interests (Midden 1988; Matejko 1988; Lipset and Schneider 1983; Bergesen and Warr 1979).

e) Credibility can be enforced by: good performance, fast responses to public requests, consonance with highly esteemed social values, availability for communication with outsiders, unequivocal and highly focused information transfer, flexibility to respond to crisis situations or new public demands, and demonstration of public control over performance and money allocation (Lipset and Schneider 1983; Rourke et al. 1976; Pinsdorf 1987).

Success stories of communication efforts in the pharmaceutical and chemical industry demonstrate clearly that overreacting to public requests never hurts (Pinsdorf 1987). Taking a product off the market even if only a tiny fraction of the product is contaminated or poisoned has helped companies in the past to manage a credibility crisis and to regain public confidence. Private institutions were more often able to show such flexibility and immediacy in their response compared to governmental institutions. But the involvement of tax money in public institutions adds a potential risk factor in the trust building effort. If too much money is spent for communication, the intended effect may be counteracted by the outrage over the spending of public money.

A model of issue organization in risk debates. The results of organizational 
studies on credibility emphasize the close relationship between perceived performance and credibility. Many risk management institutions face the problem, however, that their specific task is not well understood and that public expectations do not match the mandate or the scope of management options of the institution. This is certainly not unique for risk management agencies: Lipset and Schneider (1983) found out that elites in America complain regularly about the ignorance and misperceptions of the public with respect to their mandate and performance. Regardless of whether this claim is true, there is a clear gap between the self-perception of most institutions and the public perception of these institutions. This is specifically prevalent in the risk arena because the issue at stake, health and environment, tops the concerns of the American public and because the stochastic nature of risk impedes an unambiguous evaluation of management success or failure.

Risk communication in this situation has to address public expectations and public knowledge about the risk management rationale first before it can deal with actual management results and before it can ask for trust in the management effort. Such an educating approach is acceptable to most people only if the education process is mutual and if the essence of public concerns is adequately addressed. The first criterion-that risk managers have to learn from the public as much as the public can learn from them-has become almost a truism in communication theory. But it is still missing in communication praxis (Covello et al. 1986; Zimmermann 1987; Renn 1988). Two-way communication is clearly a prerequisite of successful information campaigns, but it is often hard to implement and requires flexibility and the willingness to adapt to public concerns on the side of the communicating institution.

The second criterion - matching communication with public concerns - is more complex and requires additional theoretical elaboration. Although twoway communication helps to identify these concerns, it is helpful to know what kind of concerns are usually expressed in the risk arena and in which way these different classes of concerns can be addressed. To classify these different classes of concerns, S. Rayner and R. Cantor have proposed a division into three levels of risk debates based on previous work of Functowitz and Ravetz on different knowledge classes (Rayner and Cantor 1987). The risk debate involves a factual level about probabilities and extent of potential damage, a clinical mode about institutional arrangements and experience to deal with these risks, and a word view perspective that is focused on values and lifestyles in dealing with risks in general. The system uncertainty and the decision stakes increase with the order of the three levels. Kasperson in 1988 proposed the possible inversion of the diagram as used by Ravetz and Rayner; this proposal is followed in Fig. 9.6 above.

We have modified this model slightly and substituted decision stakes with 


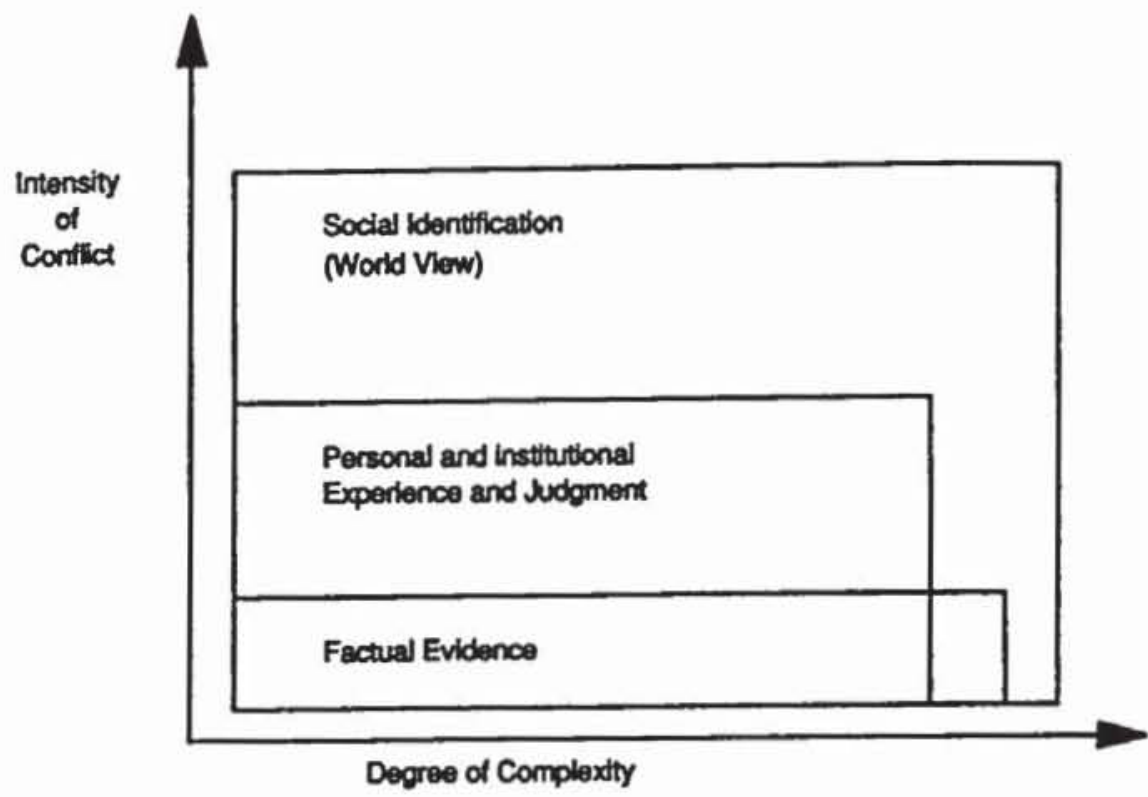

Fig. 9.6. Three analytical levels of risk communication.

"intensity of conflict" and system uncertainty with "degree of complexity." We felt that even on the lowest level of factual evidence the decision stakes might be considerable, but the conflict level is lower due to the consensus on methodological rules of scientific inquiry. System uncertainty is also related to all three levels: depending on the society, world views may encompass hardly any uncertainty whereas probabilistic reasoning in science explicitly addresses the uncertainties involved. Again we felt that degree of complexity was a more adequate term. Even simple world views are more complex than personal or institutional judgments or factual evidence. However, we could envision a higher degree of complexity in scientific evidence compared to judgmental processes. These two levels may, therefore, overlap on the category of complexity.

Figure 9.6 is a graphical representation of this model. On the lowest level, risk debates may focus on factual evidence and scientific findings. This requires a specific style and composition of the communication program. The second level represents the realm of professional judgment and experience. Past record of reasonable decision making, personal experience, and social recognition of performance are major elements for discussion here. The third level involves the personal identification with a set of values and lifestyles. Communication on this level relies on finding and establishing a shared meaning of the risk management efforts and a discussion on the role of risk management in society.

If the risk debate mainly focuses on technical issues, trust can be obtained by referring to data and scientific findings. Communication in this debate serves 
the purpose of convincing the audience that the factual knowledge compiled by independent scientists supports the case of the communicator. Although scientists and many risk management agencies are most comfortable with technical debates, they are rare in real conflicts. More probable is that the focus of the debate is on vested interests, distribution of risks and benefits, and the adequacy of the proposed solution in terms of economic and social compatibility.

This type of debate does not rely on technical expertise, but on personal and institutional judgments and experience (second level). A debate on this level requires input from stakeholder groups and affected populations. The issue of conflict is not so much the magnitude of the risk, but the distribution of risk and the tolerability of such a risk vis-a-vis the potential benefits that the risk source is able to provide. Trust in this situation cannot be accumulated by demonstrating technical skills and expertise, but by compiling evidence that the communicator has been cost-effective in the allocation of resources and has been open to public demands and requests. Competent management and openness towards social demands are the two major factors in providing credibility to an institution in the context of a risk debate on the second level.

If the participants in a risk debate focus on values and future directions of societal development (third level), neither technical expertise nor institutional competence and openness are sufficient conditions for conveying trust. Trust in this situation can only be a result of a more fundamental consensus on the issues that underlie the risk debate. The referendum on nuclear energy in Sweden can be used as an example to illustrate that point. The nuclear debate was as heated in Sweden as it was anywhere else in Europe. But through the referendum a consensus was accomplished. This consensus specified the limits for the growth of nuclear power, but also defined the legitimate range of nuclear power utilization in Sweden. This prior agreement helped to move the issue from the third to the second level where technical and organizational solutions could be discussed without expanding the debate into a fundamental conflict over lifestyles and basic values.

Most research on the effectiveness of building trust and confidence on the institutional level pertains to the second and first level of the risk debate (von Winterfeldt and Edwards 1984). The third level involves a macro-sociological framework that is hard to test empirically and that exhibits a degree of uniqueness of each single debate that it is difficult to draw generalizable conclusions. One of the common lessons learned from the study of the different risk debates is that technical and organizational solutions to a risk conflict can be implemented only if the debate never reached the third level or could successfully be removed from the third to the second level, at least for the majority of the interested audience. As long as value issues remain unresolv- 
ed, even the best expertise and the most profound competence cannot overcome the distrust that people will have in the task performance of the acting institution.

The influence of the institutional and social context. The social context in which risk communication takes place is an important factor for gaining credibility. Although the primary variables are related to the performance of the institution and its perception in the public, the overall climate towards institutions in general has a definite impact on the trust that people have in specific institutions. Research in the last two decades has produced some of the factors that influence the social climate of trust:

a) Confidence in business and economic organizations depends on the perceived quality of their services, but also on the employment situation, the perception of power monopolies in business, the observation of allegedly unethical behavior, and the confidence in other institutions, such as government or press (inverse relationship; cf. Lipset and Schneider 1983).

b) Confidence in political institutions depends on their performance record and openness, but in addition on the perception of a political crisis, the belief that government is treating everyone fair and equally, the belief in the functioning of checks and balances, the perception of hidden agendas, and the confidence in other institutions, such as business or press (inverse relationship; cf Rourke et al. 1976).

c) The more educated people are, they more they express confidence in the system, but the more they are also disappointed about the performance of the people representing the system. Less educated people express more confidence in leadership, but show less trust with respect to the system or institutions in general (Lipset and Schneider 1983).

d) Political conservatism correlates positively with confidence in business and private enterprise, and negatively with confidence in government and public service (this may be US-specific). Liberal positions are correlated with lack of confidence in both, business and government (Lipset and Schneider 1983).

In summary, social climate pre-structures the conditions under which an institution has to operate for gaining or sustaining trust. In a positive social climate, people tend to invest more trust in institutions from the beginning and may be more forgiving if part of this trust is abused. In a negative social climate people tend to be very cautious in investing trust in any institution and request to have more control over the performance of the affected institution. If trust is misused, it takes much time and effort to encourage people to start investing in the trustworthiness of the institution. 


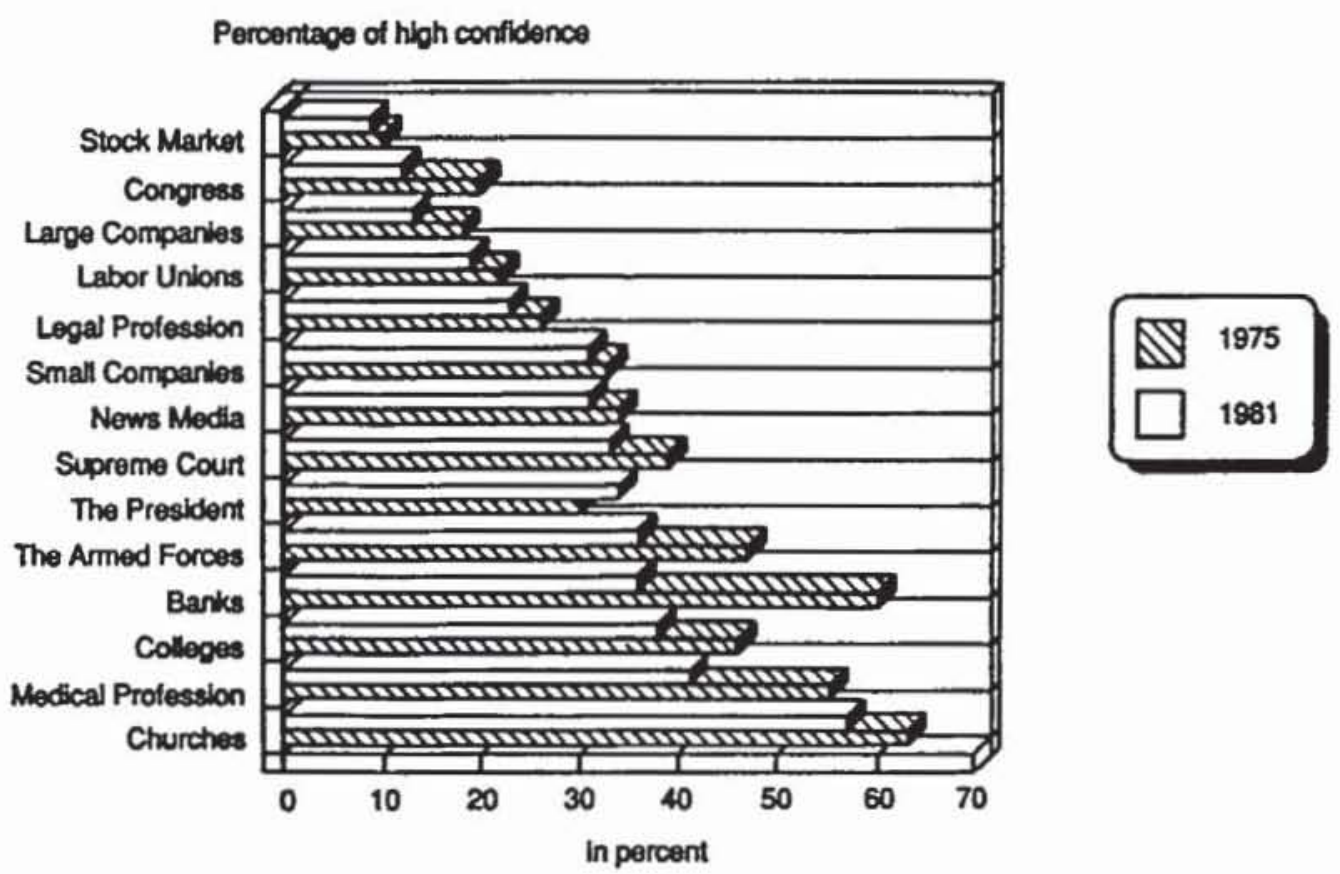

Fig. 9.7. Confidence in U.S. institutions.

Trends of public confidence in U.S. institutions

Institutional credibility. The influence of macro-sociological and economic factors on the societal level of trust, confidence, and credibility can be illustrated by survey results in the United States. In general, public confidence in all major institutions, including business, government, and labor, has declined in recent years (Lipset and Schneider 1983). The basic institutional structures of society are still supported, but may be threatened if trust continues to decline (Betz and O'Connell 1983). These trends seem to be universal for the western world, including Japan.

Figure 9.7 lists the results of a survey about the confidence of the U.S. population in selected societal institutions. The figure shows two interesting results: first, the decline in trust is universal for all selected institutions, and, second, common interest institutions, such as churches, medical institutions, and colleges, top the list of trustworthy institutions while large political institutions and big business are at the end of the scale (Lipset and Schneider 1983). Similar results were found in a survey by Renn (1984) for a West German sample about credibility of sources in the nuclear debate. Scientific and other competent institutions received high ratings compared to more general political institutions and private business. The special distinction between small business (being more trustworthy) versus big business (being less trustworthy) in the U.S. survey seems to be typical for the United States, 


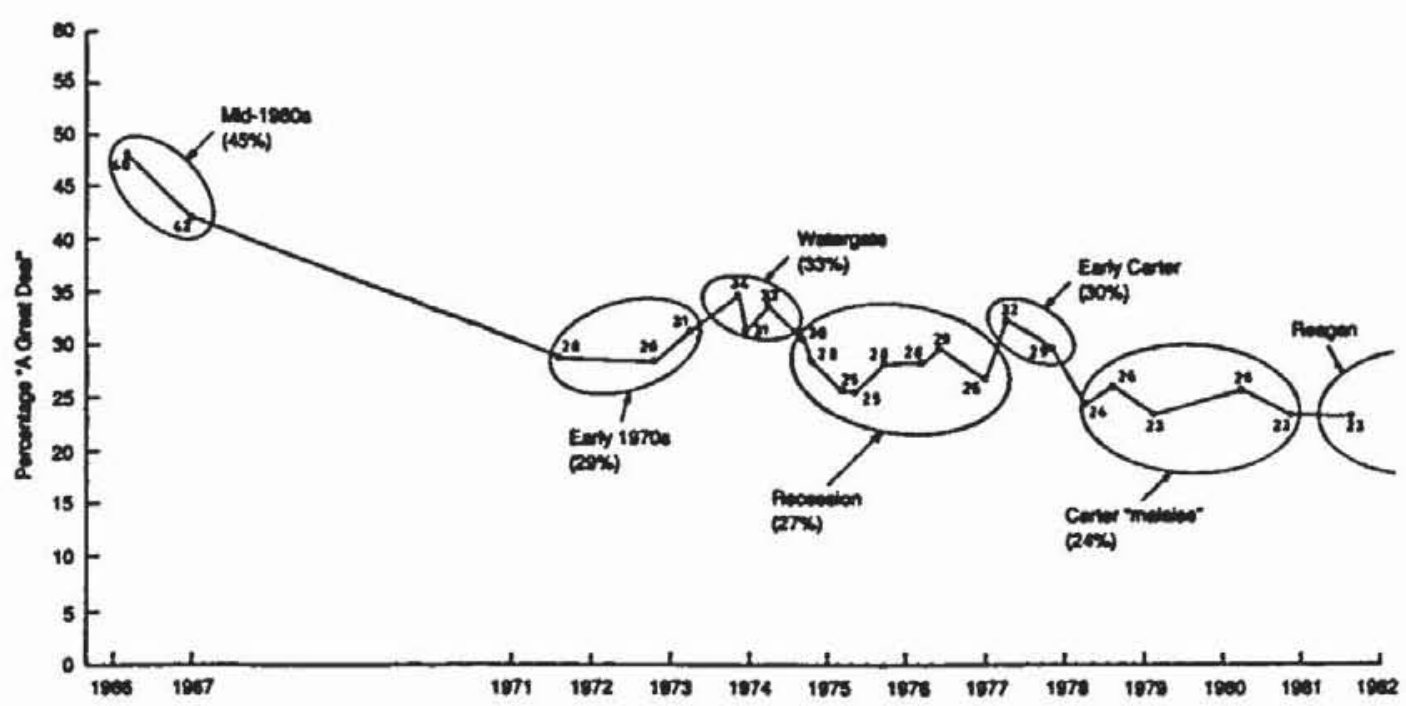

Fig. 9.8. Confidence in institutional leadership, six periods.

Sources: 24 Harris and NORC surveys. Figure taken from Lipset and Schneider (1983).

Note: Figures in parentheses show the average percentage expressing "a great deal of confidence" in the leadership of ten institutions, averaged across all polls taken in that period.

since international surveys could not reveal similar attitudes of "smaller is more trustworthy" in the United Kingdom, West Germany, Australia, and Japan (Louis Harris 1981 in Lipset and Schneider 1983).

Survey results over longer time periods demonstrate significant variations in the average assignment of confidence in institutions. In the 1930s, surveys revealed a low confidence in institutions. After the war institutional confidence improved steadily to reach a peak in the mid-1960s. During the next two decades, the confidence level dropped dramatically, but oscillated around significant events (Lipset and Schneider 1983). Figure 9.8 illustrates this trend and shows the events that apparently influenced the confidence level. The Vietnam war, the awareness of the ecological crisis, and the tremendous political turmoil in the late 1960 s probably caused the significant drop in public confidence in the early 1970 s. The Watergate scandal obviously improved the level of public confidence in institutions because the political institutions in the United States were able to handle and to overcome a serious political crisis (very positive results for the Congress and the media at that time). The following economic recession, however, started a new malaise that was shortly interrupted by a more optimistic attitude at the beginning of the Carter administration. But this administration apparently failed to meet public expectations, and so the public confidence index dropped again. Although the beginning of the Reagan era revitalized economic prosperity and optimism, the confidence in institutions hardly changed as more recent survey data suggest (University of Maryland 1985). 
Most sociologists believe that the decline of confidence in public institutions is partially a function of better education and the increase of public aspirations with respect to their share of public resources and welfare (Lipset and Schneider 1983; Katz et al. 1975). In addition, the complexity of social issues and the pluralization of values and lifestyles may have contributed to a growing dissatisfaction with the actual performance of institutions (Renn 1986). But at the same time, people are confident in the governmental and economic system and do not support fundamental changes in the organizational structure of society. Therefore, the confidence crisis is less a system than a performance or competence crisis.

The losses of confidence in public institutions show some peculiar patterns. The less people have confidence in one class of institutions, the more they are inclined to assign more trust to those institutions that are either functional equivalents or control institutions for this specific institution (Lipset and Schneider 1983). The more people distrust the government, the more they trust private business and vice versa. People apparently feel more comfortable in investing a fixed minimal amount of overall trust to different institutions and distribute this amount according to their preferences. Figure 9.9 illustrates this relationship of mutual compensation for the executive branch and the press. In time periods where confidence in the executive branch is low, people are inclined to express confidence in the press and the other way around. This mutual compensation scheme can also serve as evidence for the strong commitment of the American public to the idea of check and balances.

Public confidence in institutions was more negative if the institutions were listed in general terms. The general label "public utilities" triggered more negative responses than more concrete options, such as "Your local public utility company," or any utility company's name (Lipset and Schneider 1983). This result may be an artifact since many respondents might have no recollection of negative events with respect to their local company, but plenty of memories on public utilities in general (availability effect). But this result could also be an indication that most people are actually satisfied with the personal service they receive from these organizations, but that they get a picture of the outside world through the media and personal networks that suggests more negative experiences and abuses of trust for people outside of the community. If this interpretation is valid, the affected institutions may all perform perfectly, but still face a credibility crisis due to the perception that the more abstract notion of an institutional type or class to which the specific institutions belong is associated with a negative image. The change of such an image may require a time-consuming effort to demonstrate positive performance and to link the specific accomplishments of one organization to the pool of organizations with which it is associated. 


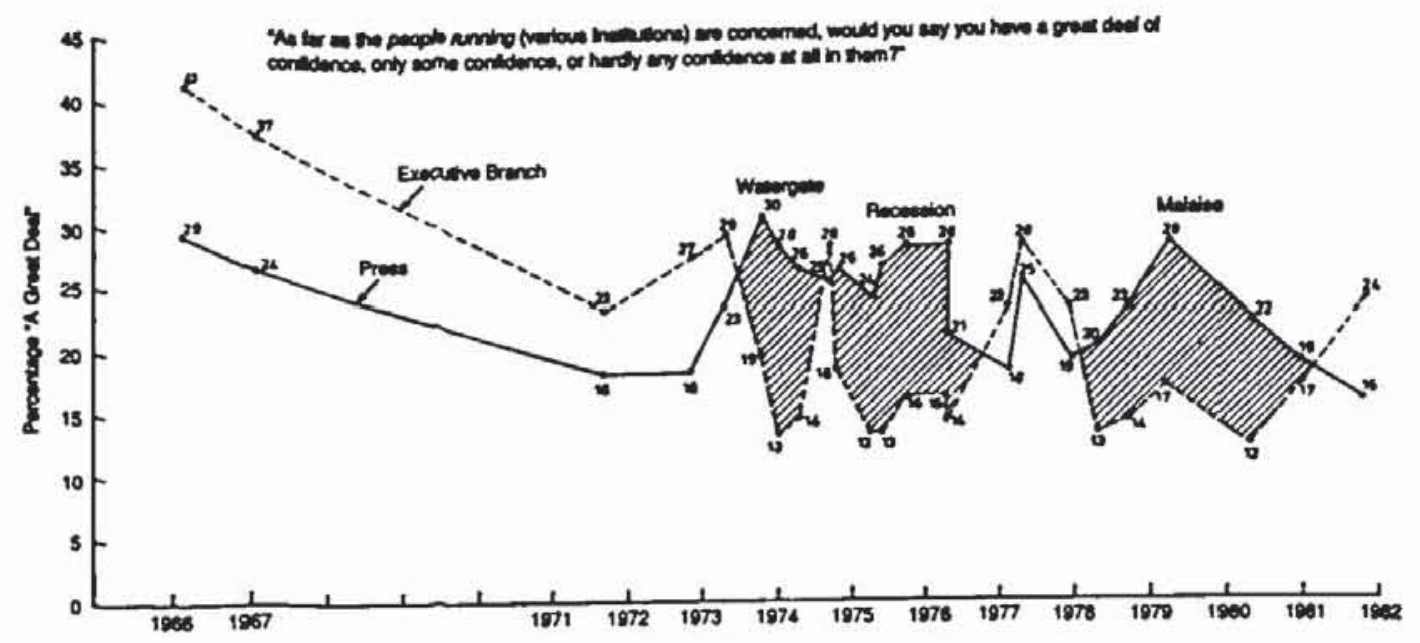

Fig. 9.9. Relationship between confidence in the executive branch and in the press, 1966-1981. Sources: 24 Harris and NORC surveys. Figure taken from Lipset and Schneider (1983).

Credibility in science and technology. Risk management can be associated with economic or political institutions and is therefore subject to the same social forces of growing distrust that other institutions face in the contemporary U.S. society. Since distrust is not directed towards the structure or the system of the institutions, but rather to their performance and leadership, some authors have proposed that the crisis is caused by a deep distrust of the American public toward professionals and cultural elites (Betz and O'Connell 1983). Again this scepticism towards elites is not a novel feature in U.S. history and can be traced back to the birth of the nation. But the increased functional dependency of a modern economy and a modern political system on professional elites may have revitalized and aggravated public dissatisfaction (Lipset and Schneider 1983). The election of Jimmy Carter as a representative of the anti-establishment and the popularity of Ronald Reagan as a symbol that common sense and a "simple" set of values are sufficient to run a country like the United States can be interpreted as reflections of this general resentment against professionalism.

Risk communication may face this resentment in particular because risk analysis and risk management rely on highly professionalized rules and often run counter to common sense. Peripherally interested persons are probably more susceptible to such a resentment because it offers a readily available cue to dismiss the information offered by risk management institutions. But even an elaborate processing of each argument presented may activate an unfavorable response if the language and the reasoning appear too technical and remote from everyday-life experiences.

But in spite of this opposition to professionalism, people's trust in science and technology is higher than in most other professional institutions. While 
opinion polls show a decline of confidence in Congress from 42 to 13 percent; in colleges, from 61 to 36 percent; and in medicine from 72 to 43 percent, science suffered only a loss of nine percent (from 46 to 37 ) during the decade from 1966 to 1976 (Betz and O'Connell 1983). Table 9.2 lists the percentages of respondents that indicate a great deal of confidence in the people running selected professional institutions. (One should notice that the data of this table do not match the percentages depicted in Fig. 9.7. A slight difference in wording and scaling has caused these differences. Although the numbers do not match, the underlying trends are still identical). Table 9.2 shows that professional institutions in general lost credibility over the last decade, but that the scientific community remained almost stable in spite of some dramatic fluctuations from one year to the next.

But this overall impression of a favorable and rather stable credibility of scientific institutions has to be further qualified. The attitudes of the general public toward science and technology may still be overwhelmingly favorable, but there is increasing evidence that the minority voicing negative opinions of science and technology, though still small, does seem to have grown during the last 20 years and that persons of the typically supportive middle class also are

Table 9.2. Public indicating "a great deal of confidence" in the people running selected institutions: $1973-86$.

\begin{tabular}{|c|c|c|c|c|c|c|c|c|c|c|c|}
\hline Institution & 1973 & 1974 & 1975 & 1976 & 1977 & 1978 & 1980 & 1982 & 1983 & 1984 & 1986 \\
\hline & & & & & & Percer & $\mathrm{nt}$ - & & & & \\
\hline Medicine & 54 & 60 & 50 & 54 & 51 & 46 & 52 & 46 & 51 & 50 & 46 \\
\hline Scientific community & 37 & 45 & 38 & 43 & 41 & 36 & 41 & 38 & 41 & 44 & 39 \\
\hline Education & 37 & 49 & 31 & 37 & 41 & 28 & 30 & 33 & 29 & 28 & 28 \\
\hline Organized religion & 35 & 44 & 24 & 30 & 40 & 31 & 35 & 32 & 28 & 31 & 25 \\
\hline Military & 32 & 40 & 35 & 39 & 36 & 29 & 28 & 31 & 29 & 36 & 31 \\
\hline Major companies & 29 & 31 & 19 & 22 & 27 & 22 & 27 & 23 & 24 & 30 & 24 \\
\hline Press & 23 & 26 & 24 & 28 & 25 & 20 & 22 & 18 & 13 & 17 & 18 \\
\hline TV & 19 & 23 & 18 & 19 & 17 & 14 & 16 & 14 & 12 & 14 & 15 \\
\hline Organized labor & 15 & 18 & 10 & 12 & 15 & 11 & 15 & 12 & 8 & 8 & 8 \\
\hline $\begin{array}{l}\text { Executive branch of the } \\
\text { federal government }\end{array}$ & 29 & 14 & 13 & 13 & 28 & 12 & 12 & 19 & 13 & 18 & 21 \\
\hline Congress & 23 & 17 & 13 & 14 & 19 & 13 & 9 & 13 & 10 & 12 & 16 \\
\hline U.S. Supreme Court & 31 & 33 & 31 & 35 & 35 & 28 & 25 & 30 & 28 & 33 & 30 \\
\hline $\begin{array}{l}\text { Banks and } \\
\text { financial institutions }\end{array}$ & NA & NA & 32 & 39 & 42 & 33 & 32 & 25 & 24 & 31 & 21 \\
\hline $\mathrm{N}=$ & 1,504 & 1,484 & 1,490 & 1,499 & 1,530 & 1,532 & 1,468 & 1,506 & 1,599 & 989 & 1,470 \\
\hline
\end{tabular}

Sources: James A. Davis, Tom W. Smith, General Social Surveys Cumulative Codebook 19721985, Roper Center, pp. 166-169; unpublished 1986 data provided by Tom W. Smith. 
disproportionately more aware and concerned about such technological hazards as pollution and nuclear arms (Pion and Lipsey 1981:313).

The reasons for a more sceptical or at least ambiguous perception of science and technology are routed in at least three different developments (Renn 1984): First, after two decades of astonishing successes in scientific accomplishments, aspirations in the future applications of science exploded and led to expectations that problems such as cancer or world hunger could be resolved by science within a short time period. As these expectations remained unfulfilled, people became more sceptical and disenchanted. Second, the rise of the environmental movement and the awareness of the environmental crisis acted as reinforcers to the disappointment over the slow scientific progress and revealed the ambiguity of technical development. Third, the shift from quantitative to qualitative goals, a typical development in most western nations, induced a fuzzier perception of the merits and objectives of scientific and technological activities. The definition of what constitutes a good quality of life entailed a variety of often conflicting interests and goals that were often in opposition to the implicit values and interests of the scientific and technological community.

In addition to these more fundamental factors, other influences and developments have been suggested as causes for the increased scepticism toward science: the alignment of science to big business and government, anxiety about the ethical implications of further technological advances in some areas of medicine and the biological sciences, and the growing awareness that much scientific research lacks social relevance (La Porte and Metlay 1975). Lack of confidence in science is more pronounced among those who are young and who identify themselves as "liberal" and "conservationist" (Lipset and Schneider 1983; La Porte and Metlay 1975).

The decline of confidence in science and technology has major impacts on risk communication. Even within technical debates that require expertise as a means to provide trust, people have no means to study or review the evidence presented. They do not possess a lab and cannot afford to employ a scientist to investigate the various claims. Even scientific reputation or evidence of peer review may not be sufficient to convince the audience that an information is technically correct, let alone that it is relevant for the issue in question. One of the solutions in this dilemma is either to lift the debate to the second or third level, where common sense and prior experience provide enough knowledge to take part in the debate, or to initiate a sophisticated institutional framework of check and balances that assures scientific scrutiny and control.

In spite of this difficulty, risk communication should emphasize the scientific roots of risk analysis and risk management and refer to scientific conventions as a means to reconcile conflicts about facts. Among the professional stan- 
dards that guide risk management efforts, scientific standards are more likely to be accepted by a lay audience than, for example, institutional rules. If these standards can be expressed in common sense concepts and applied to everyday-experience (not just a translation into everyday-language), the probability of trust in the message will further increase.

Risk management institutions have to live with the overall climate of distrust in contemporary society and the deep scepticism toward professionalism. Although it makes risk communication definitely more difficult, one should not forget that this public scrutiny has served the political culture of the United States and prevented radical changes towards a more totalitarian government and abuses of economic or political power. The political arena conditions of the risk debate should be regarded as a challenge for communication rather than a target for change.

\section{Specific aspects of trust in risk communication}

In the introduction to this chapter, we discussed some specific contingencies of the risk arena and its implications for risk communication. Many people have difficulties in understanding the meaning of probabilities (see also Chapter 5). Linked with the concept of probability is the problem that the success of risk management is difficult to measure. Reducing the overall probability of an adverse event may not show any visible effects and does not preclude the event from happening. The preoccupation of society with environmental problems, the perceived ambiguity of technical change, and the overall decline of trust in public institutions predestine risk debates to evolve to third level controversies and to become issues of lifestyle and world view (Rayner 1987; Renn 1986). This expansion of the risk issue from a technical to an institutional one and furthermore to a world view issue is accompanied by a social clustering process into two antagonistic social camps that have assembled their own scientific support system and that compete for social resources in the risk arena. The resulting conflict produces conflicting evidence, further erosion of trust, and personal frustration. In this situation, risk communication has to meet an almost impossible task: to develop a framework of mutual trust and confidence so that conflicts can be reconciled in a rational and democratic way.

What advice can we give to risk communicators of how to design and implement a risk communication program that incorporates the findings of past research and includes the more anecdotal evidence of risk communication efforts in the past? The first lesson is to distinguish among the three levels of the debate. Nothing is more detrimental and frustrating for all participants involved than addressing an audience who expects a third level debate and is 
confronted with a detailed technical analysis of the issue. The risk communicator should investigate the level of debate beforehand and design different communication programs for each level.

Debates change frequently in nature and it is important to have the means available to switch from a technical, to an institutional and moral debate. Whereas technical expertise is vital on the first level and evidence for institutional competence and openness on the second, there is no clear medium of communication available for the third level. A more general discourse focused on value issues may be the appropriate tool. If the objective of such a debate is to reconcile existing conflicts, the involvement of an outside mediator may be helpful in setting the agenda and in identifying the concerns and values that the communicator is supposed to address.

Using our analytical model for distinguishing between message, person, institution, and social climate, we have developed a set of conditions and prerequisites for gaining trust in communicating with others. These refer to preconditions for risk communication and provide orientations for analyzing and designing communication programs:

a) To improve the trust in a message, we recommend explaining the rationale of risk analysis and its role for risk management so that the audience is better prepared as to what to expect. In addition, the decision making process and the past record of the institution should be included in the message so that people can assign competence to the actors and get a better feeling of the trade-offs that had to be made in meeting the specific risk management task. Evidence of competence, fairness towards other viewpoints, and references to commonly shared values and beliefs will make a message more attractive and could help to address the centrally and peripherally interested audience at the same time. Conclusions should be made explicit and vested interests should not only be admitted, but justified in terms of public mandate or economic function.

b) To improve trust in a personal communicator, the major goal is to develop a communication climate that enables the audience to identify with the communicator and to share his or her experiences and beliefs. The more a communicator manages to avoid the mask of an institutional spokesperson and the more he or she can express compassion and empathy for the audience, the more likely the audience will identify with the speaker and feel compelled to the arguments. As noted throughout this book, conveying probabilistic information is a real challenge, but can be done in reference to everyday experience of budget constraints and consumer products. Furthermore, evidence of successful use of risk analyses in hazard management can serve as demonstration to define the role and limitations of risk analysis 
in improving public health and the environment. Peripheral cues should be confined to commonly shared symbols, appealing formats, and surprises in openness and honesty and should definitely avoid negative labelling of potential opponents or typical advertising gimmicks. Peripheral cues are important for successful communication, but cues have to be selected carefully to please the peripherally and centrally interested audience alike.

c) To improve the credibility of an institution, the vital factor is performance, not public relations. Confidence has to be gained by meeting the institutional goals and objectives. In addition, credibility is linked to the evidence of being cost-effective and open to public demands. These two goals are often in conflict with each other (Kasperson 1987), but they have to be treated as complementary, and not as substitutional, goals. Fairness and flexibility are major elements of openness. In addition to assuring sufficient external control and supervision, public participation may be implemented as a means to demonstrate the compliance with the political mandate and to avoid the impression of hidden agendas. On the premise of good performance, communication programs can be designed that reflect these accomplishments. Such programs should provide honest, complete, and accurate information that is responsive to the needs and demands of the prospective audience. This can only be done if the source engages in an organized effort to collect feedback from the audience and establish a two-way communication process. Involvement of citizens, open house policies, discussion forums, open TV channels, or other means should be explored to assure the functioning of the two-way communication structure.

d) To improve the social climate is not within the realm of possibilities for a single communicator. But large-scale organizations or association of organizations can affect the overall climate. One way to improve the climate is to accept and even endorse checks and balances in the control of the organization. The other obvious solution is to demonstrate the flexibility and foresight of the organization in meeting and anticipating new public claims and values. The impersonal nature of institutions may be mitigated by providing special local services and by engaging in community activities and programs. Governmental institutions will receive more credibility if they do not leave the impression of permanent crisis management, but of competence and preparedness for long-term threats and challenges (in particular pertaining to environment and technology).

Many different factors affect credibility. On the personal level, appearance, communication style, honesty, and creating an atmosphere of identification of the audience with the communicator are major variables that influence cred- 
ibility. On the institutional level, the actual performance in terms of role fulfilment, cost-effectiveness and public expectations as well as openness to new claims and demands constitute confidence and help to build credibility. Furthermore, the social climate and the level of controversy associated with the issue affect the assignment of credibility independent of the performance of the actors involved.

\section{Conclusions}

The objective of this chapter has been to review the relevant psychological and sociological literature on trust and credibility in communication and to apply the findings of our search to the new area of risk communication. What are the major insights gained from our review and how may they be practically applied to risk communication programs?

Psychological and sociological research cannot provide solutions to these problems. As Kasperson and Stallen point out in their introduction to this book, the communicator who expects recipes or fool-proof guidelines for dealing with the public will certainly not find them in the literature or in risk communication experience. The major finding of all the experiments and surveys conducted so far is that individuals as well as social units make use of a complex variety of internal and external cues to process messages and that the variation of one or two factors may only lead to marginal changes in the outcome. As hard as it is to make predictions from existing cues to attitude changes or from attitudes to actual behavioral responses (Wicker 1979), the more difficult it is to create a communicative environment that guarantees the desired persuasive effect.

With this reservation in mind, studies about persuasion and institutional credibility provide interesting findings directly relevant for risk communication. First, and most important, credibility of a communication source is closely linked to the perceived past performance record and its openness for public demands. The more that institutions comply with the expectations of the public, the more confidence people will have in these institutions and the more trust they will assign to their messages. Communication efforts may be successful to change excessive aspirations or to correct misperceptions of the actual performance record, but it is more than unlikely that communication can compensate poor performance.

Furthermore, in a climate of general distrust toward social organizations, it is helpful to accept countervailing powers and public control and to provide public access to all relevant information. On the basis of these structural opportunities for public involvement and control, specific communication 
programs can be designed that include elements of successful persuasion. How can one make a message attractive provided that the information given is accurate, complete, and honest?

The major recommendation is to assess the concerns of the targeted audience before drafting the message (Kasperson and Palmlund) forthcoming. Are the concerns related to technical matters (such as emissions or potential health effects), to institutional performance and judgments (such as the decision to ban a substance from the market and tolerate another), or to values and world views (such as the tolerability of large-scale technologies or the inequities involved in centralized production or waste disposal facilities)?

Depending on the level of concerns in the actual risk debate, the communication program has to be designed and implemented in a different way. Technical debates need input from technical experts and scientists and must rely on clear evidence that the risk assessment of the communicator reflects the best available estimate. Institutional debates need the input of senior management staff and outside control agencies who can give testimony about the past record of the institution and independent reviews of its performance. Valuedriven debates are the most difficult to handle and most institutions avoid dealing with them. But credibility is easily lost if third level concerns are ignored or, even worse, addressed with technical or legal arguments. It seems advisable to open a discourse with different stakeholder groups, social scientists, moral authorities, and public opinion leaders as a means to clarify one's own values and to document their legitimation in a value-pluralistic society.

Finally, the message and the personal appeal of the communicator can be improved by following some of the general lessons described above. The major thrust of these guidelines refer to the inclusion of verbal cues and elements of personal appearance that make the audience identify with the message or a communicator and relate to their personal experience and shared values. Technical jargon (even in technically oriented debates), reference to professional wisdom (versus common sense), emphasis on common practice, and impersonal approach are some of the cues that communicators should avoid. The more the audience feels that the message means something to them or that the communicator is "one of them," the more they will be inclined to listen to the message and process its content.

Since credibility plays a major role in the selection and evaluation of messages, the messages should contain enough cues to emphasize their validity. Reference to uncommitted and neutral experts that share the intent of the message, justification of vested interests, explicit disclosure of motives (rather than having the audience speculate about them), and giving a fair, but clear rejection of the arguments used by persons with opposing viewpoints, are tools in the quest for credibility. 
The order in which these conclusions were presented reflect the order of importance and effectiveness. A good communication program should not start with communication at all, but with a critical review of the organizational structure and the potentials within this structure to meet the demand for openness and public involvement. Then a thorough analysis of the issues is needed to identify public concerns and characterize the risk debate. Lastly comes the design of the communication program, with the formulation of the message, its proper packaging, channelling, sending, and testing in terms of communicative feedback.

By carefully framing the information, by tailoring the content to the needs of the final receivers, and by conveying a clear, honest, and appealing message, risk communication can convey a basic understanding for the choices and constraints of risk management. It can thus create the foundations for gaining trust and credibility. Although many receivers of risk information may not agree with the actual decisions institutions have made in setting priorities or selecting management options, they may realize that these decisions are results of open discussions and painful trade-offs.

\section{Acknowledgement}

The research described in this chapter was funded by a grant from the Program Group "Technology and Society" of the Research Center Jülich. I would like to thank Professor H. Jungermann, Professor R. Kasperson, Professor. C. Midden, and Dr. Wiedemann for their helpful comments on an earlier draft of this paper.

\section{References}

Allen, F.W. 1987. Towards a holistic appreciation of risk: The challenge for communicators and policymakers. Science, Technology, and Human Values 12 (Summer/Fall): 138-143.

Anderson, C. 1983. Abstract and concrete data in the perseverance of social theories: When weak data lead to unshakeable beliefs. Environmental Social Psychology 19: 93-108.

Barber, B. 1983. The logic and limits of trust. New Brunswick, NJ: Rutgers University Press.

Beck, U. 1986. Die Risikogesellschaft. Auf dem Weg in eine andere Moderne. Frankfurt, a.M.: Suhrkamp.

Betz, M. and L. O'Connell. 1983. Changing doctor-patient relations and the rise in concern for accountability. Social Problems 19 (October): 31-42.

Blair, E.H. 1987. Discussion on responsibilities of risk communication. In: J.C. Davies, V.T. Covello, and F.W. Allen (eds), Risk communication. Washington, DC: The Conservation Foundation, 35-38. 
Brown, J. 1987. Biotechnology: public attitudes and policy implications. Paper presented to 6 th Environmental Psychology Conference, University of California: Irvine, May 14th-16th.

Burnham, J.C. 1982. American medicine's golden age: What happened to it? Science 215 (March): 1474-1480.

Chaiken, S. and C. Stangor. 1987. Attitudes and attitude change. Annual Review of Psychology 38: $575-630$.

Chaiken, S. 1980. Heuristic versus systematic information processing and the use of source versus message cues in persuasion. Personality and Social Psychology 39: 752-766.

Cotton, J.L. 1985. Cognitive dissonance in selective exposure. In D. Zillman and J. Byrant (eds), Selective exposure to communication. Hillsdale, NJ: Erlbaum, 11-33.

Covello, V.T. 1983. The perception of technological risks: A literature review. Technological Forecasting and Social Change 23: 285-297.

Covello, V.T., D. von Winterfeldt and P. Slovic. 1986. Risk communication: A review of the literature. Risk Abstracts 3(4): 171-182.

Covello, V.T. 1987. Risk comparisons, risk communication, and public perceptions of risk: Issues and approaches. Manuscript. Washington: National Science Foundation.

Crawford, M. 1986. Larger public sector role sought on biotech. Science 232 (April): 15-16.

Douglas, M. 1985. Risk acceptability according to the social sciences. New York, NY: Russell Sage Foundation.

Douglas, M. and A. Wildavsky. 1982. Risk and culture. Berkeley: University of California Press.

Deutsch, M. 1973. The resolution of conflict: constructive and destructive processes. New Haven, CT: Yale University Press.

Durkheim, E. 1933 (orig. 1893). The division of labor in society. New York: The Free Press.

Eagly, A.H., S. Chaiken and W. Wood. 1981. An attribution analysis of persuasion. In J.H. Harvey, W.J. Ickes, and R.F. Kidd (eds.), New directions in attribution research. Hillsdale, NJ: Erlbaum, 37-62.

Eagly, A.H. and S. Chaiken. 1984. Cognitive theories of persuasion. Advances in Experimental Social Psychology 17: 268-359.

Einhorn, H.J. and R.M. Hogarth. 1978. Confidence in judgment: Persistence in the illusion of validity. Psychological Review 85: 395-416.

Fazio, R.H., M.P. Zanna and J. Cooper. 1977. Dissonance and self-perception: An integrative view of each theory's proper domain of application. Experimental Social Psychology 13: 464-479.

Festinger, L. 1957. A theory of cognitive dissonance. Stanford, CA: Stanford University Press.

Fishbein, M. and J. Ajzen. 1975. Belief, attitude, intention, and behavior: An introduction to theory and research. Reading, MA: Addison Wesley.

Fischhoff, B., S. Lichtenstein, P. Slovic, S. Derby and R. Keeney. 1982. Acceptable risk. Cambridge: Cambridge University Press.

Frey, D. 1986. Recent research on selective exposure to information. Advances in Experimental Social Psychology 19: 41-80.

Garfinkel, H. 1967. Studies in ethnomethodology. Englewood Cliffs, NJ: Prentice-Hall.

Goldoftas, B. 1982. Recombinant DNA: The ups and downs of regulation. Technology Review (May/June): 29-34.

Gricar, B. and A. J. Baratta. 1983. Bridging the information gap at Three Mile Island: Radiation monitoring by citizens. Applied Behavioral Science 19. No. 1 (January): 35-49.

Hance, B.J., C. Chess and Peter Sandman (eds.). 1988. Improving Dialogue with Communities. Trenton, NJ: New Jersey Department of Environmental Protection.

Heesacker, M., R.E. Petty and J.T. Cacioppo. 1983. Field dependence and attitude change: 
Source credibility can alter persuasion by affecting message-relevant thinking. Personality and Social Psychology 51: 401-413.

Hoos, I. 1980. Risk assessment in social perspective. In National Council on Radiation Protection and Measurements (ed), Perceptions of risk. Washington, DC: NCR, 37-85.

Hovland, C.I. and W. Weiss. 1967. The influence of source credibility on communication effectiveness. In R.L. Rosnow and E.J. Robinson (eds), Experiments in persuasion. New York, NY: Academic Press, 9-24.

Huber, J. 1984. Die verlorene Unschuld der Okologie. Frankfurt/M.

Jungermann, H. 1982. Zur Wahrnehmung und Akzeptierung des Risikos von GroBtechnologien. Psychologische Rundschau 33: 217-238.

Jungermann, H. and R.S. May. 1988. Die psychologische Kognition und Evaluation von Risiko. In G. Bechmann (ed), Risiko und Gesellschaft. Opladen: Westdeutscher Verlag.

Kahneman, K. and A. Tversky. 1974. Judgement under uncertainty heuristies and biases. Science 185: 1124-1131.

Kasperson, R.E., O. Renn, P. Slovic et al. 1988. The social amplification of risk: A conceptual framework. Risk Analysis 8(2) (August): 177-187.

Kasperson, R.E. 1987. Trust and credibility: The central issue? In: J.C. Davies, V.T. Covello, and F.W. Allen (eds), Risk Communication Washington, D.C.: The Conservation Foundation, 43-46.

Kasperson, R.E. and I. Palmlund. 1987. Evaluating risk communication. Unpublished Manuscript Worcester, MA.

Kasperson, R.E. 1986. Six propositions for public participation and their relevance for risk communication. Risk Analysis, 6(3): 275-281.

Kaz, D., B.A. Gatek, R.L. Kahn and E. Barton. 1975. Bureaucratic encounters. Institute for Social Research, Ann Harbor, MI: University of Michigan.

Keeney, R.L. and D. von Winterfeldt. 1986. Improving risk communication. Risk Analysis 6: 417-424.

Krieger, J.H. 1982. Public acceptance of nuclear power declining. Chemical and Engineering News, 1 (January 18): 73-79.

LaPorte, T.R. and D. Metlay. 1975. Technology observed: Attitudes of a wary public. Science 188 (April ): 121-127.

Lee, T.R. 1986. Effective communication of information about chemical hazards. The Science of the Total Environment 51: 149-183.

Lichter, R.S. and S. Rothman. 1983. Scientists' attitudes towards nuclear energy. Nature 305 (September).

Lipset, S.M., and W. Schneider. 1983. The confidence gap: business, labor, and government, in the public mind. New York: The Free Press.

Luhmann, N. 1986. Okologische Kommunikation. Westdeutscher Verlag: Opladen.

Luhmann, N. 1980. Trust and power. New York: Wiley.

Luhmann, N. 1973. Vertrauen: Ein Mechanismus der Reduktion sozialer Komplexität, 2. Edition Enke: Stuttgart.

Lynn, F.M. 1986. The interplay of science and values in assessing and regulating environmental risks. Science, Technology, and Human Values 11 (Spring): 40-50.

Matejko, A.J. 1988. The sociotechnical perspective on trust at work. Speyerer Arbeitshefte 86: 1-251.

Meinefeld, W. 1977. Einstellung und soziales Handeln. Reinbek, FRG: Rowohlt.

McCallum, D. 1987. Risk factors for cardiovascular disease: Cholesterol, salt, and high blood pressure. In J.C. Davies, V.T. Covello, and F.W. Allen (eds), Risk communication. Washington, D.C.: The Conservation Foundation, 67-70. 
McCormick, D. 1985. What public debate? Biotechnology 3 (November): 205-207.

McGuire, W.J. 1985. Attitude and attitude change. In G. Lindzey and E. Aronson (eds), Handbook of social psychology, 3rd edition, New York: Random House 2: 223-346.

McKenzie, R.B., and W. F. Shughart II. 1987. Deregulation and air travel safety. Regulation 3/4: 40-51.

Midden, C. 1988, Credibility and risk communication. Paper for the International Workshop on Risk Communication, October 17-20, 1988. Jülich: Nuclear Research Center.

Parker, L. 1988. Safety board hearings focusing public attention rather than solving crisis. Washington Post (July 29): A23.

Parsons, T.E. 1960. Pattern variables revisited. American Sociological Review 25: 467-483.

Parsons, T.E. and E.A. Shils (eds). 1951. Toward a general theory of action. Cambridge: Cambridge University Press.

Perrow, C. 1984. Normal accidents. New York,: Basic Books.

Peters, H.P., G. Albrecht, L. Hennen and H.U. Stegelmann. 1987. Die Reaktionen der Bevölkerung auf die Ereignisse in Tschernobyl. Ergebnisse einer Befragung. Report of the Nuclear Research Center, Jülich, F.R.G., Jül-Spez-400 (KFA: May 1987).

Petty, R.E. and E. Cacioppo. 1986. The elaboration likelihood model of persuasion. Advances in Experimental Social Psychology 19: 123-205.

Pinsdorf, M. 1987. Communicating when your company is under siege. Lexington, MA, and Toronto, Canada: Lexington Books.

Pion, G.M. and M. W. Lipsey. 1981. Public attitudes toward science and technology: What have the surveys told us? Public Opinion Quarterly 45: 303-316.

Public attitudes toward nuclear power. Public Opinion Index 10 (October 1983): 1-12.

Rayner, S. 1987. Risk and relativism in science for policy. In B.B. Johnson and V.T. Covello (eds), The social and cultural construction of risk. New York: Reidel.

Rayner, S. and R. Cantor. 1987. How fair is safe enough? The cultural approach to societal technology choice. Risk Analysis 7: 3-10.

Rempel, J.K., J.G. Holmes and M.P. Zanna. 1985. Trust in close relationships. Personality and Social Psychology 49: 95-112.

Rempel, J.K. and J.G. Holmes 1986. How do I trust thee? Psychology Today 2 (February): 28-34.

Renn, O. 1987. Evaluation of risk communication: Concepts, strategies, and guidelines. In Managing environmental risks; Proceedings of an APCA International Speciality Conference in Washington D.C., October 1987. Washington, DC: APCA, 99-127.

Renn, O. 1986. Akzeptanzforschung: Technik in der gesellschaftlichen Auseinandersetzung. Chemie in unserer Zeit 2: 44-52.

Renn, O. 1984. Risikowahrnehmung der Kernenergie. New York: Campus.

Rokeach, M. 1969. Beliefs, attitudes, and values. Berkeley: California University Press.

Rosnow, R.L. and E.J. Robinson (eds). 1967. Experiments in persuasion. New York: Academic Press.

Rourke, F.E., L. Free and W. Watts. 1976. Trust and confidence in the American system. Washington, DC: Potomac Assoc.

Rotte, J.B. 1980. Interpersonal trust, trustworthiness, and gullibility. American Psychologist 35: 1-7.

Scanzoni, J. Social exchange and behavioral interdependence. In R.L. Burgess and T.L. Huston (eds.), Social exchange in developing relationships. New York: Academic Press.

Shannon, C.E. and W. Weaver. 1949. The mathematical theory of communication. Urbana, IL: University of Illinois Press.

Sheridan, T.B. 1985. Trustworthiness of command and control systems. Unpublished Manuscript. Cambridge, MA: MIT. 
Slovic, P., B. Fischhoff and S. Lichtenstein. 1981. Perception and acceptability of risk from energy systems. In A. Baum and J.E. Singer (eds), Advances in environmental psychology Vol. 3, Energy psychological perspectives. Hillsdale, NJ: Ertlbaum.

Slovic, P. 1987. Perception of risk. Science 236: 280-285.

Sun, M. 1986. White House to release biotechnology guidelines. Science 210: 124-125.

Tetlock, P.E. 1986. A value pluralism model of ideological reasoning. Personality and Social Psychology 48: 819-827.

Tyler, T.R. 1984. The role of perceived injustice in defendants' evaluations of their courtroom experience. Law Sociology Review 18: S1-74.

Tversky, A. and D. Kahneman. 1975. Judgement under uncertainty: Heuristics and biases. In D. Wendt and C. Vlek (eds), Utility, probability and human decision making. North Holland: Dordrecht and Boston, 141-162.

University of Maryland, Center for Philosophy and Public Policy. 1985. Faith in science. Unpublished Manuscript. College Park: University of Maryland.

U.S. General Accounting Office. 1988. Aviation safety: Measuring how safely individual airlines operate? Washington,: U.S. GAO.

von Winterfeldt, D. and W. Edwards. 1984. Patterns of conflict about risk debates. Risk Analysis 4 (March): 55-68.

Grove, P. 1965. Webster's third new international dictionary. 1965. Springfield, MA: Mirriam.

Wicker, A.W. 1979. Attitudes vs actions: The relationship of verbal and behavioral responses to attitude objects. Journal of Social Issues 22: 41-78.

Wolfe, A.K. 1986. Confidence in technologies: Interactions between publics and industries. Paper presented at the Annual Meetings of the Society for Risk Analysis, November 11, Boston, MA.

Zimmermann, R. 1987. A process framework for risk communication. Science, Technology, and Human Values 12 (Summer/Fall): 131-137. 